\title{
CircRNAs in anticancer drug resistance: recent advances and future potential
}

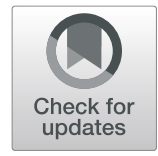

\author{
Tianwei $\mathrm{Xu}^{1 \dagger}$, Mengwei Wang ${ }^{1 \dagger}$, Lihua Jiang ${ }^{1 \dagger}$, $\mathrm{Li} \mathrm{Ma}^{1 \dagger}$, Li Wan², Qinnan Chen ${ }^{1}$, Chenchen Wei ${ }^{1 *}$ and \\ Zhaoxia Wang ${ }^{\text {* }}$
}

\begin{abstract}
CircRNAs are a novel class of RNA molecules with a unique closed continuous loop structure. CircRNAs are abundant in eukaryotic cells, have unique stability and tissue specificity, and can play a biological regulatory role at various levels, such as transcriptional and posttranscriptional levels. Numerous studies have indicated that circRNAs serve a crucial purpose in cancer biology. CircRNAs regulate tumor behavioral phenotypes such as proliferation and migration through various molecular mechanisms, such as miRNA sponging, transcriptional regulation, and protein interaction. Recently, several reports have demonstrated that they are also deeply involved in resistance to anticancer drugs, from traditional chemotherapeutic drugs to targeted and immunotherapeutic drugs. This review is the first to summarize the latest research on circRNAs in anticancer drug resistance based on drug classification and to discuss their potential clinical applications.
\end{abstract}

Keywords: Circular RNA, Cancer, Drug, Resistance

\section{Introduction}

Cancer has become the most serious public health problem worldwide [1]. As the early diagnosis of cancer urgently needs to be improved, many patients are already suffering from advanced cancer at the first clinical visit [2]. These patients miss the opportunity for surgery, and anticancer drugs are their major treatment option. Since the first clinical report of chemotherapy for advanced cancers, multiple anticancer drugs have been developed and have effectively improved the clinical outcomes of patients with advanced cancers [3]. In addition, targeted and immunotherapeutic drugs have recently ushered in a new era in medical therapy for cancer $[4,5]$. However, anticancer drug resistance still cannot be avoided, resulting in cancer relapse. The mechanisms underlying anticancer drug resistance are multifaceted. Different hallmarks such

\footnotetext{
*Correspondence: wangzhaoxia@njmu.edu.cn; weichenchen1990@126.com †Tianwei Xu, Mengwei Wang, Lihua Jiang and Li Ma contributed equally to this work.

${ }^{1}$ Cancer Medical Center, The Second Affiliated Hospital of Nanjing Medical University, Jiangjiayuan road 121\#, Nanjing 210011, Jiangsu, P.R. China Full list of author information is available at the end of the article
}

as tumor growth, selective therapeutic pressure, immune system characteristics and the tumor microenvironment determine the biological behaviors of anticancer drug resistance [6]. These hallmarks are driven by complex underlying molecular regulatory mechanisms [7]. Identifying the key molecules in these processes could help us to understand the occurrence of resistance, and these molecules play considerable roles in the prediction and reversion of anticancer drug resistance [8].

With the development of sequencing, studies have shown that approximately $70 \%$ of the human genome is transcribed, but only $2 \%$ encodes proteins [9]. The remaining RNA, which does not encode proteins, was initially thought to be transcriptional junk [10]. Accumulating evidence has revealed that these noncoding RNAs (ncRNAs) also exert a great influence on physiological activities and pathological changes, especially in cancer [11, 12]. Importantly, ncRNAs are classified by size into small RNAs such as miRNAs ( $22 \mathrm{nt})$ and long non-coding RNAs (lncRNAs, $>200 \mathrm{nt}$ ). Dysregulation of ncRNAs participates in the molecular and cellular 
processes related to cancer. The roles of ncRNAs are divided into oncogenes and tumor suppressors, based on their effect on the cancer. For example, miR-21 was reported to promote tumor growth and metastasis by targeting PTEN in lung cancer and other cancers, such as melanoma and B cell lymphoma $[13,14]$. As shown in our previous study, high serum miR-21 levels indicate a poor prognosis for patients with non-small cell lung cancer (NSCLC) [15]. In contrast, miR-34a functions as a direct downstream target of p53 to block cancer progression [16]. HOTAIR, a well-studied oncogenic lncRNA, is generally upregulated in cancers and epigenetically silences tumor suppressors such as p21 [17]. However, lncRNA MEG3 modulates the expression of p53 and some other tumor suppressors to increases chemotherapeutic sensitivity [18]. Several ncRNAs may also function as either tumor suppressors or oncogenes, depending on the context. For example, the lncRNA NKILA reduces cancer metastasis by negatively regulating NF-kB signaling, while it also promotes tumor immune evasion [19]. Since ncRNAs such as miRNAs and lncRNAs have been confirmed to play an important role in cancer, studies of new ncRNAs will continue to improve our understanding of cancer.

In recent years, a novel class of lncRNAs designated circular RNAs (circRNAs) has also been identified and extensively studied in cancer biology [20]. CircRNAs are derived from pre-mRNAs through a non-canonical alternative splicing event called backsplicing. This process endows circRNAs with a unique fundamental structural feature that differs from common linear IncRNAs, namely, a covalently closed continuous loop structure without a polyadenylated tail. CircRNAs are very stable because their unique structure is resistant to exonuclease-mediated degradation [21].

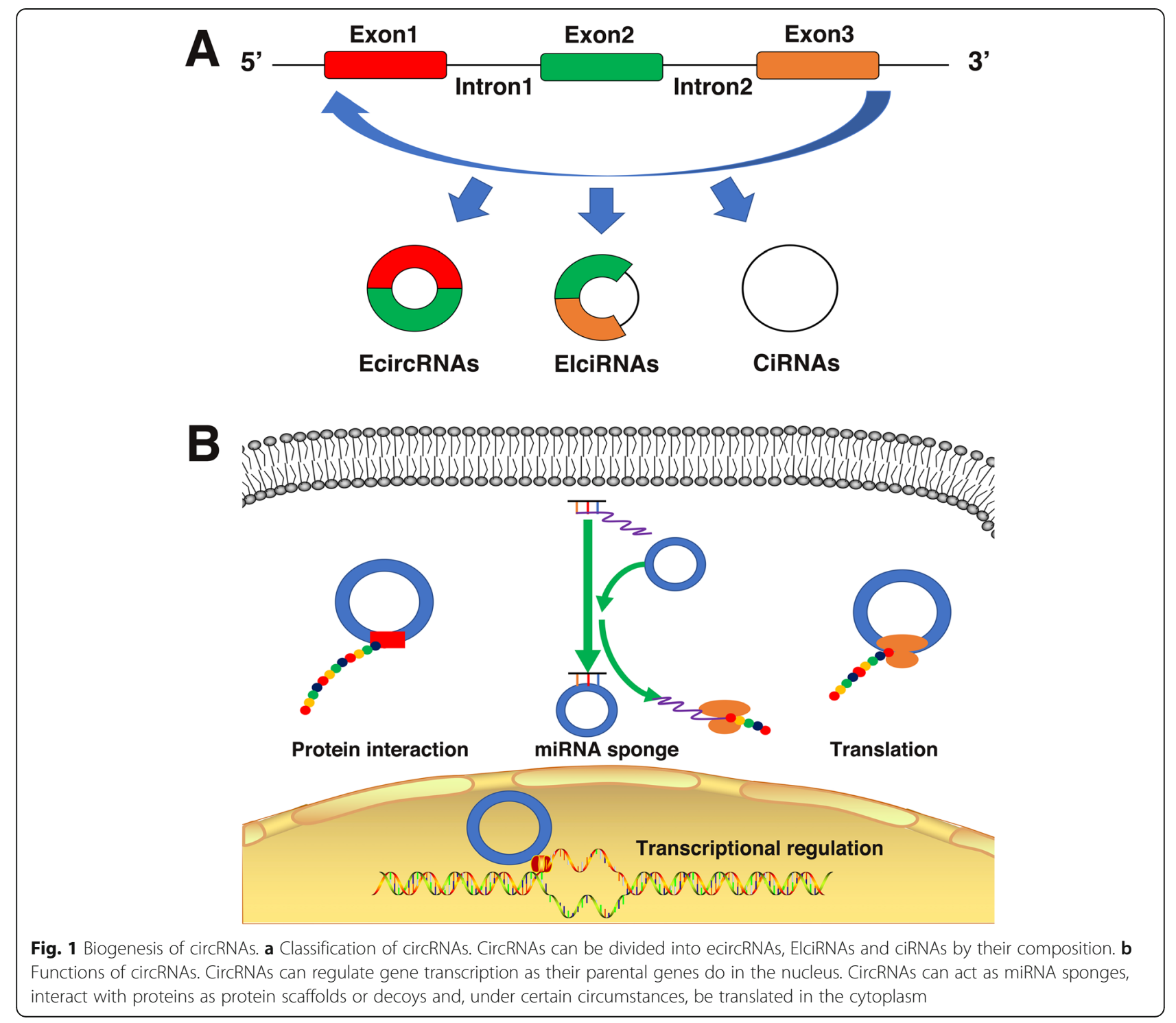


Although backsplicing is much less efficient than canonical splicing in linear RNAs, circRNAs are still enriched in tissues, serum and even urine [22]. Although circRNAs are widely expressed, the expression pattern of circRNAs displays tissue specificity and cell type specificity. For example, platelets express more circRNAs than neutrophils, which are also blood cells (3324 vs 274 circRNAs) [23, 24].CircRNAs can be divided into 3 subtypes: 1) exonic circRNAs (EcircRNAs), which contain only exon sequences; 2) intronic circRNAs (ciRNAs), which contain only intron sequences; and 3) exon-intron circRNAs (EIciRNAs), which contain both exon and intron sequences [25] (Fig. 1a). Studies have demonstrated that circRNAs may exert biological functions by transcriptional regulation, miRNA sponging, protein interactions or, under certain circumstances, self-translation [26, 27] (Fig. 1b). For example, ciRS-7 is a well-known circRNA that is enriched in neuronal tissues. CiRS-7 knockout mice exhibit neuropsychiatric disorders, and the underlying mechanism may be attributed to the ciRS-7/miR-7/Fos axis [28].

CircRNAs also participate in various pathological processes, including the development of cancer [22]. According to the classification of the mechanism in tumors, we present some representative circRNAs with clear mechanisms, biological functions and clinical significance (Table 1). First, circRNAs are differentially expressed in almost all cancers, including lung cancer, gastrointestinal cancers and urological cancers. Second, circRNAs are differentially expressed, rather than simply upregulated or downregulated in the same tumor. For example, circPVT1 and circFADS2 are upregulated [32, 33 ] and circNOL10 and circPTPRA are downregulated in lung cancer $[29,34]$. Third, the same circRNAs are also differentially expressed in a variety of tumors, but the upregulated or downregulated expression patterns are not the same in different tumors. CircHIPK3 is

Table 1 Representative circRNAs with clear mechanisms, biological functions and clinical significance in cancers

\begin{tabular}{|c|c|c|c|c|c|c|}
\hline Mechanism & Cancer & CircRNA & Expression & Biological functions & Clinical significance & Ref \\
\hline \multirow[t]{3}{*}{$\begin{array}{l}\text { Transcriptional } \\
\text { regulation }\end{array}$} & Lung cancer & circNOL10 & Down & $\begin{array}{l}\text { Inhibit cell proliferation and promote cell } \\
\text { apoptosis; }\end{array}$ & Lung cancer differentiation & [29] \\
\hline & $\begin{array}{l}\text { Colorectal } \\
\text { Cancer }\end{array}$ & circlTGA7 & Down & Inhibit cell growth and metastasis; & $\begin{array}{l}\text { Tumor size; } \\
\text { Lymph metastasis; Distant metastasis } \\
\text { and TNM stage; }\end{array}$ & {$[30]$} \\
\hline & Breast Cancer & circFECR1 & Up & Promotes tumor metastasis; & Metastases; Advanced stages; & [31] \\
\hline \multirow[t]{11}{*}{$\begin{array}{l}\text { MiRNA } \\
\text { sponging }\end{array}$} & Lung cancer & circPVT1 & Up & $\begin{array}{l}\text { Promote cell proliferation and Inhibit cell } \\
\text { apoptosis; }\end{array}$ & Tumor size; TNM stage; Overall survival; & {$[32]$} \\
\hline & & circFADS2 & Up & Promote proliferation and invasion; & TNM; LNM; Overall survival; & {$[33]$} \\
\hline & & circPTPRA & Down & Inhibit proliferation and migration; & Metastasis; Overall survival; & {$[34]$} \\
\hline & Gastric Cancer & circHIPK3 & Up & Promote proliferation and migration; & $\begin{array}{l}\text { Overall survival; Infiltrative type GC cell; } \\
\text { Advanced TNM stage; }\end{array}$ & $\begin{array}{l}{[35,} \\
36]\end{array}$ \\
\hline & & circPVT1 & Up & Promote proliferation; & Overall survival; Disease-free survival; & {$[37]$} \\
\hline & & circLARP4 & Down & Inhibit proliferation and invasion; & Overall survival; & {$[38]$} \\
\hline & $\begin{array}{l}\text { Colorectal } \\
\text { cancer }\end{array}$ & circHIPK3 & Up & $\begin{array}{l}\text { Promote proliferation, migration, invasion, } \\
\text { metastasis, autophagy and inhibit } \\
\text { apoptosis; }\end{array}$ & $\begin{array}{l}\text { Advanced TNM stage; Lymph node } \\
\text { metastasis, Distant metastasis; Advanced } \\
\text { tumor; }\end{array}$ & [39] \\
\hline & & 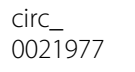 & Down & $\begin{array}{l}\text { Inhibit proliferation, migration, and } \\
\text { invasion; }\end{array}$ & $\begin{array}{l}\text { TNM stage; } \\
\text { Overall survival; }\end{array}$ & {$[40]$} \\
\hline & $\begin{array}{l}\text { Hepatocellular } \\
\text { carcinoma }\end{array}$ & circHIPK3 & Up & Proliferation, migration & $\begin{array}{l}\text { Tumor differentiation; Advanced TNM } \\
\text { stage; HBV-DNA copy numbers; Liver } \\
\text { cirrhosis; }\end{array}$ & [41] \\
\hline & & 0001649 & Down & Inhibit proliferation and migration & $\begin{array}{l}\text { Differentiation and tumor } \\
\text { Satellite; }\end{array}$ & {$[42]$} \\
\hline & Bladder cancer & circHIPK3 & Down & $\begin{array}{l}\text { Inhibit Migration, invasion and } \\
\text { angiogenesis. }\end{array}$ & $\begin{array}{l}\text { Advanced tumor; Lymph node } \\
\text { metastasis; }\end{array}$ & {$[43]$} \\
\hline \multirow[t]{2}{*}{$\begin{array}{l}\text { Protein } \\
\text { interaction }\end{array}$} & Gastric cancer & $\begin{array}{l}\text { circ- } \\
\text { DONSON }\end{array}$ & Up & Facilitate cancer growth and invasion & $\begin{array}{l}\text { TNM stage; Lymph node metastasis; } \\
\text { Overall survival and Disease-free survival; }\end{array}$ & {$[44]$} \\
\hline & & circAGO2 & Up & Promote growth, invasion, and metastasis & Metastasis; Overall survival; & {$[45]$} \\
\hline \multirow[t]{2}{*}{ Self-translation } & Glioblastoma & $\begin{array}{l}\text { Circ-SHPR } \\
\mathrm{H}\end{array}$ & Down & $\begin{array}{l}\text { Suppress tumor progression and } \\
\text { tumorigenesis }\end{array}$ & Overall survival; & [46] \\
\hline & & circFBXW7 & Down & $\begin{array}{l}\text { Inhibit proliferation and cell cycle } \\
\text { acceleration. }\end{array}$ & Overall survival; & {$[47]$} \\
\hline
\end{tabular}


upregulated in most types of cancers, such as gastric cancer, colorectal cancer and hepatocellular carcinoma [35, 36, 39, 41]. However, it is downregulated in bladder cancer [43]. Based on these findings, the expression pattern of circRNAs in malignant tumors is very complex, and thus a high-throughput detection method is needed to determine the differential expression profile of circRNAs to further understand the importance of the differential expression patterns of circRNAs in cancer.

The complex expression pattern of circRNAs also implies complex biological functions and clinical significance in cancer. CircRNAs modulate multiple biological functions of cancer, such as proliferation, metastasis and angiogenesis [30, 31]. For example, circPVT1 promotes cell proliferation and inhibits cell apoptosis in lung cancer [32] and gastric cancer [37], while circHIPK3 inhibits angiogenesis in bladder cancer [43]. CircRNAs have important tumor-related clinical significance and are associated with various clinical features of cancer and patient outcomes. As shown in Table 1, the clinical features of cancer mainly include cancer differentiation, lymph node metastasis, distant metastasis and the TNM stage [40, 42]. The association between circRNAs and the clinical characteristics of tumors suggests the potential diagnostic value of circRNAs. For example, low circNOL10 expression may indicate a low level of differentiation of lung cancer [29]. High circDONSON expression suggests that clinicians should closely monitor lymph node metastasis in patients with gastric cancer [44]. The main circRNA-related indicators of outcomes in patients with cancer are overall survival and disease-free survival [44, 45]. In patients with gastric cancer, high circPVT1 expression indicates poor overall survival and disease-free survival [37], while high circLARP4 expression is related to longer overall survival [38]. CircFBXW7 and circ-SHPRH are good prognostic biomarkers for glioblastoma because their high expression results in longer overall survival [46, 47]. In conclusion, the important role of circRNAs in tumors must not be ignored. Moreover, the crucial role of circRNAs in mediating anticancer drug resistance is emerging [48]. Here, we are the first to summarize the role of circRNAs in anticancer drug resistance from the perspective of drug classification.

\section{Nonplatinum cytotoxic drugs}

Traditional anticancer drugs can be divided into cell cycle-specific anticancer drugs and cell cycle-nonspecific anticancer drugs according to their cellular kinetics [49, 50]. Classical cell cycle-specific drugs include topoisomerase inhibitors, antimetabolite drugs and some drugs derived from plants [51-53]. Typical cell cycle-nonspecific anticancer drugs are anticancer antibiotics [54].

\section{Topoisomerase inhibitors}

Topoisomerase is abundantly distributed in all eukaryotic nuclei and resolves topological problems during bioprocesses such as DNA replication and DNA transcription [55]. In the 1970s, camptothecin was found to have anticancer activity, and topoisomerase I was identified as its major target [56]. Irinotecan is an Sphase-specific camptothecin derivative that exerts efficient anticancer activity against metastatic colorectal cancer (CRC) [57]. However, clinical resistance to irinotecan is common [58]. Jian et al. [59] found that circ_ 001680 increases migration and is involved in irinotecan resistance in CRC. Circ_001680 acts as an oncogene by sponging miR-340 to upregulate BMI1 in CRC. BMI1 has been recognized as a positive regulator that induces cancer stem cell-like properties [60, 61], which are deeply involved in irinotecan resistance [62, 63]. Sphere formation assays showed that SW480 and HCT116 cells with circ_001680 overexpression formed more stem cell spheres after treatment with irinotecan and had a more robust cell growth ability than control cells. In vivo, the sizes and weights of tumors in the control group were markedly decreased after treatment with irinotecan but were not significantly changed in the circ_001680-overexpressing group. These results indicate that the circ 001680/miR-340/BMI1 axis may contribute to irinotecan resistance by regulating cancer stem cell-like properties.

\section{Antimetabolite drugs}

Pemetrexed is a folate antagonist that disrupts folatedependent metabolic processes $[64,65]$. It functions mainly during S-phase. Xu et al. [66] reported a novel circRNA, circMTHFD2, related to pemetrexed resistance in gastric cancer. Overexpression of circMTHFD2 was confirmed in pemetrexed-resistant gastric cancer cells. Further investigation showed that circMTHFD2 could bind with miR-124 and promote the protein expression of FDZ5 and MDR-1 to induce pemetrexed resistance. 5-Fluorouracil (5-FU), a fluoropyrimidine, can inhibit thymidylate synthase to induce thymineless cell death and functions mainly as an S-phase antimetabolite [67, 68]. 5-FU has been the standard treatment for many solid tumors, including CRC, for decades $[69,70]$. The benefit of 5-FU is always limited by the development of resistance, and the specific molecular mechanisms are complex [71]. Xiong et al. [72] identified 71 differentially expressed circRNAs in 5-FU-resistant CRC cells by microarray hybridization. Forty-seven of these circRNAs were upregulated, and 24 were downregulated. These circRNAs were distributed on each chromosome, but most were located on chromosomes 1,8 , and 9 (11, 10, and $10 \%$, respectively), suggesting that these 3 chromosomes are more strongly correlated with 5-FU resistance than other chromosomes. The top 3 most strongly 
upregulated circRNAs were predicted to be capable of regulating the Wnt signaling pathway, which is deeply involved in 5-FU resistance [73]. In addition, several 5FU-resistance-related miRNAs, such as miR-885-3p [74], may be targets of these circRNAs.

Gemcitabine is another widely used S-phase antimetabolite drug [75]. Yan et al. [76] reported that circ_0035483 is significantly increased in TK10 and UO31 renal cancer cell lines after treatment with gemcitabine. The results of an MTT assay showed that high expression of circ 0035483 in gemcitabine-treated TK10 cells could enhance cell viability to induce gemcitabine resistance. The results of RNA pulldown experiments revealed that circ_0035483 can bind with miR-335 as a sponge. Further dualluciferase assay results identified CCNB1 as a target of miR-335. CCNB1 is an important checkpoint molecule in the cell cycle and is deeply involved in cell cycle-specific gemcitabine resistance [77, 78]. Promotion of circ 0035483 expression increased the expression of CCNB1, and cell apoptosis was inhibited. Thus, circ_0035483 promotes gemcitabine resistance in human renal cancer cells by sponging miR-335 to upregulate CCNB1.

Gemcitabine resistance can also be developed by selection under exposure to an increasing gradient of gemcitabine in pancreatic cancer (PC) cell lines [79]. The gemcitabine-resistant SW1990/GZ cell line was developed from the parental SW1990 cell line, and 81 circRNAs were found to be differentially expressed between this cell line and the parental cell line [80]. Twenty-six of these circRNAs were upregulated, and 55 were downregulated. Four circRNAs were validated by qRT-PCR. Pathway analysis indicated that these dysregulated circRNAs are deeply involved in gemcitabine resistance in PC via modulation of MAPK and mTOR signaling pathways $[81,82]$.

In addition, Shao et al. [83] established the gemcitabine-resistant PANC-1-GR cell line and compared the differential circRNA profiles between the PANC-1-GR cell line and the parental PANC-1 cell line. A total of 126 circRNAs were identified by highthroughput transcriptome sequencing as significantly differentially expressed in these two cell lines; 68 of which were upregulated and 58 downregulated. Moreover, gene ontology (GO) term and pathway analysis results indicated the functions of these circRNAs in PC progression-related signaling pathways, such as the ErbB pathway [84]. The two most significantly upregulated circRNAs (chr14:101402109-101,464,448+ and chr4: 52729603-52,780,244+) were further validated, and functional experiments showed that silencing these two circRNAs restored gemcitabine sensitivity in PANC-1GR cells, while overexpression of these circRNAs promoted gemcitabine resistance in both the PANC-1 and MIA PACA-2 cell lines. Identification of potential binding miRNAs of these two circRNAs by sequence analysis suggested that miR-145-5p, a tumor suppressor inhibiting PC progression [85], could bind both circRNAs and act as a downstream target. Moreover, the plasma expression levels of the two circRNAs and miR145-5p in gemcitabine-treated PC patients were verified via $\mathrm{qRT}$-PCR. Consistent with previous results, the two circRNAs were upregulated but miR-145-5p was downregulated in the plasma of gemcitabine-resistant patients. This finding confirms their potential for monitoring gemcitabine resistance via liquid biopsy.

\section{Drugs derived from plants}

Taxol is an M-phase specific plant drug that was originally derived from the bark of the Pacific yew and has become one of the most widely used agents [86]. Unlike antimetabolite drugs, Taxol can bind tubulin to arrest mitosis and induce apoptosis, resulting in cell death [87]. The mechanism underlying Taxol resistance remains poorly understood [88]; however, ncRNA dysregulation plays an important role in this process [89, 90]. Taxol is an effective chemotherapeutic drug in first-line therapy for gastric cancer [91]. Liu et al. [92] reported that circPVT1, a circRNA derived from the oncogenic IncRNA PVT1 locus [93], can mediate Taxol resistance in gastric cancer. Overexpression of circPVT1 was confirmed both in Taxol-resistant gastric cancer tissues and cells, and circPVT1 knockdown promoted apoptosis triggered by Taxol. ZEB1 is a well-known promoter of Taxol resistance $[94,95]$. Mechanistically, circPVT1 can promote ZEB1 expression by sponging miR-124-3p. In addition, Taxol resistance remains problematic in the treatment of ovarian cancer [96, 97]. Expression profiles of dysregulated circRNAs were identified in Taxolresistant ovarian cancer tissues. A total of 833 aberrantly expressed circRNAs were found; 341 were upregulated and 492 downregulated [98]. Among these circRNAs, circ_0063809 was further confirmed by qPCR to be upregulated in both Taxol-resistant tissues and cells. In vitro and vivo experiments demonstrated that silencing circ_0063809 promotes Taxol-induced cytotoxicity in Taxol-resistant ovarian cancer cells. Moreover, the results of mechanistic experiments revealed that circ 0063809 can upregulate FOXR2 expression by sponging miR-1252 to contribute to Taxol resistance in ovarian cancer. Taxol is also recommended for first-line treatment of HER2-negative metastatic breast cancer (BC) [99]. CircAMOTL1 was found to contribute to Taxol resistance by activating the AKT pathway [100].

$\mathrm{Xu}$ et al. [101] reported the differentially expressed circRNA profile in the Taxol-resistant A549/Taxol cell line compared to the parental A549 cell line. A total of 11, 281 circRNAs were identified, among which 2909 circRNAs were upregulated and 8372 were downregulated. 
GO analysis results showed that the most significantly enriched terms were linked to Taxol resistance-related terms, such as GTPase binding and alterations in cell adhesion [102, 103]. In addition, Cytoscape was used to visualize the circRNA-miRNA interaction network. Several miRNAs previously reported to drive Taxol resistance were predicted. For example, miR-141 has been suggested to induce Taxol resistance in ovarian cancer [104], and miR-34c-5p can downregulate p53 to induce Taxol resistance in lung cancer [105]. Circ_0071799, which was upregulated, is related to miR-141. Downregulated circ_0091931 can interact with miR-34c-5p. In addition, Li et al. [106] reported that circ_0002483 overexpression can enhance Taxol sensitivity in non-small cell lung cancer (NSCLC). Circ_0002483 has been confirmed by a dual-luciferase reporter assay to sponge miR-182-5p, and pathway analysis revealed that the circ 0002483/miR-182-5p interaction may be deeply involved in the FoxO signaling pathway. Further analysis indicated that the $3^{\prime}$ untranslated regions (3'-UTRs) of GRB2, FOXO1 and FOXO2 contain miR-182-5p complementary sequences. Mechanistically, the circ 0002483/miR-182-5p/GRB2/FOXO1/FOXO3 axis can reverse Taxol resistance in NSCLC.

$\mathrm{Yu}$ et al. [107] evaluated the overexpression of circ 0003998 in the docetaxel-resistant lung adenocarcinoma A549/DTX and H1299/DTX cell lines. Knockdown of circ_0003998 in A549/DTX and H1299/DTX cells partially restored docetaxel sensitivity via promotion of cell apoptosis. In addition, miR-326 was predicted by the Circular RNA Interactome (CircInteractome) database [108] as a potential target of circ_0003998. MiR-326 is a well-recognized tumor suppressor, and its downregulation is deeply involved in multidrug resistance in tumors [109], and a significant negative correlation between circ_0003998 expression and miR-326 expression was found in lung adenocarcinoma tissues. Further dualluciferase reporter assays confirmed the direct binding between circ_0003998 and miR-326. In addition, miR326 inhibitors were found to significantly reverse the increased sensitivity to docetaxel caused by circ 0003998 siRNA. In summary, overexpression of circ 0003998 induces docetaxel resistance in lung adenocarcinoma partially by sponging of miR-326. Docetaxel can also be used in first-line chemotherapy for patients with metastatic nasopharyngeal carcinoma (NPC) [110]. Hong et al. [111] reported that circCRIM1 binds to miR-422a to upregulate FOXQ1 in NPC. FOXQ1 is intimately involved in chemotherapeutic resistance by regulating the epithelial-mesenchymal transition (EMT) [112]. In vivo and in vitro functional experiments have confirmed that FOXQ1 overexpression induced by circCRIM1 also contributes to metastasis and docetaxel resistance in NPC [111].

\section{Anticancer antibiotics}

As a cell cycle-nonspecific anticancer drug, doxorubicin (Adriamycin) is an anthracycline antibiotic antineoplastic drug widely used in the clinic [113]. Its underlying anticancer mechanisms are inhibition of DNA synthesis, interference with topoisomerase II activity and induction of free radical damage to cells [54]. CircRNAs have also been reported to play a role in doxorubicin resistance. The differential expression profile of circRNAs in a doxorubicin-resistant acute myeloid leukemia (AML) cell line (THP-1/ADM) was identified by analysis of a human circRNA array. Forty-nine circRNAs were found to be differentially expressed with a fold change of $>2$ in THP-1/ADM cells compared to THP-1 cells. Thirty-five were upregulated, and 14 were downregulated. Among these circRNAs, circPAN3 was considered a candidate mediator of doxorubicin resistance due to its substantial differential expression and the important role of its host gene PAN3 in AML [114]. In addition, circPAN3 expression was higher in the bone marrow of patients with refractory/recurrent AML than in the bone marrow of doxorubicin-sensitive patients. Moreover, knockdown of circPAN3 reversed doxorubicin resistance in THP-1/ ADM cells. TargetScan showed that miR-153-5p and miR-183-5p could be target genes of circPAN3. XIAP, a well-known chemoresistance-related gene in AML [115], was found to be a downstream target of both miR-153-5p and miR-183-5p. Further mechanistic experiments also confirmed the circPAN3/miR-153-5p/miR-183-5p/XIAP axis, which contributes to doxorubicin resistance in AML.

Doxorubicin has also been approved by the FDA for clinical use in patients with BC [116]. The results of a microarray screen also indicated the important role of circRNAs in doxorubicin resistance in BC [117]. Eighteen circRNAs were identified as significantly differentially expressed between doxorubicin-resistant MCF-7/ADM and doxorubicin-sensitive MCF-7 cells; 12 were upregulated, while 6 were downregulated. Kyoto Encyclopedia of Genes and Genomes (KEGG) analysis revealed that the most relevant signaling pathways included the MAPK and PI3K/Akt signaling pathways, which are closely related to doxorubicin resistance [118, 119]. In addition, circ_0006528 expression was measured by qRT-PCR. The results confirmed circ 0006528 overexpression in doxorubicin-resistant cell lines and tissues. Downregulation of circ_0006528 restored the sensitivity of MCF-7/ADM and MDA-MB-231/ADM cells to doxorubicin. Moreover, miR-7-5p, which has been reported to be involved in PI3K/Akt signaling pathway activation and chemoresistance in $\mathrm{BC}$ [120], was predicted to be a target of circ_0006528, while Raf1, a MAPK signaling pathway activator, is a direct target of miR-7-5p [121]. Further experimental results proved that the circ_0006528/ miR-7-5p/Raf1 axis may be responsible for doxorubicin resistance in $\mathrm{BC}$. 
CircKDM4C was reported by Liang et al. to be a tumor suppressor in BC [122]. In vitro experiments identified decreased expression of circKDM4C in MDAMB-231/DOX cells compared with the parental MDAMB-231 cells. CircKDM4C knockdown in MDA-MB231 cells promoted resistance to doxorubicin, while overexpression of circKDM4C in MDA-MB-231/DOX cells inhibited cell proliferation, enhanced apoptosis and finally reversed doxorubicin resistance in dosedependent and time-dependent manners. MiR-548p was predicted by CircInteractome database analysis to be a target of circKDM4C, and upregulation of miR-548p was found to partially abolish circKDM4C overexpressioninduced inhibition of doxorubicin resistance. Further miRNA target prediction indicated that the 3 '-UTR of phenazine biosynthesis-like domain-containing protein (PBLD) is considered a putative target of miR-548p. PBLD is associated with various tumor progressionrelated signaling pathways, such as the MAPK pathway [123]. Luciferase reporter assay results confirmed the circKDM4C/miR-548p/PBLD axis, and the contribution of this axis to doxorubicin resistance was proven both in vitro and in vivo.

\section{Platinum drugs}

Platinum drugs such as cisplatin and oxaliplatin are widely used in the treatment of human cancers and have achieved clinical success as standard therapies [124]. Oxaliplatin is a platinum complex with oxalate and (1R, 2R)-1,2-diaminocyclohexane (DACH) ligands. Oxaliplatin uptake has been reported to be mediated by the organic cation transporters OCT1 and OCT2, which are overexpressed in CRC cells [125]. This overexpression partially explains why oxaliplatin is an efficient component in the adjuvant FOLFOX treatment regimen in metastatic CRC. Oxaliplatin resistance has become an issue in CRC. Drug-resistant HCT116 (HCT116-R) cells were developed by exposure to FOLFOX, and circRNA microarray analysis was performed to compare circRNA expression profiles between HCT116-R and parental HCT116 cells [126]. A total of 773 upregulated and 732 downregulated circRNAs were identified. The presence of two upregulated circRNAs, circ_32883 and circ_0338, in extracellular vesicles was further validated. Circ 32883 was found to be significantly upregulated in CRC tissues. Several microRNAs, such as miR-501-5p, were predicted to interact with circ_32883 to bind to their target genes. Hon et al. [127] isolated exosomes from the cell culture medium of HCT116-R and parental HCT116 cells and used by circRNA microarray analysis to identify 105 significantly upregulated and 34 downregulated circRNAs. Consistent with a previous report, circ_32883 and circ_0338 were upregulated in HCT116$\mathrm{R}$ cell-derived exosomes. In addition, the resistance of
HCT116-R cells to FOLFOX was partially reversed by knockdown of circ_0338, indicating a potential role for circ_0338 as a biomarker for FOLFOX resistance in CRC. Wang et al. [128] identified a novel circRNA, circ_ 0005963, in exosomes derived from oxaliplatin-resistant CRC cells. This circRNA could be transferred into oxaliplatin-sensitive CRC cells and promote glycolysis and oxaliplatin resistance in the recipient cells. Further experiments showed that circ_0005963 can sponge miR122 to upregulate PKM2. In addition, si-circ_0005963 transferred by exosomes inhibited glycolysis and reversed resistance to oxaliplatin. Thus, this exosomally initiated circ_0005963/miR-122/PKM2 signaling axis has great therapeutic potential for oxaliplatin-resistant CRC.

Cisplatin was first synthesized by Michele Peyrone and was approved by the US FDA for use in testicular and ovarian cancer in 1979 [129]. Cisplatin often leads to an initial therapeutic response, but many originally sensitive tumors gradually develop resistance [130]. Huang et al. [131] screened 31 circRNAs derived from EIF3a, the largest subunit of the translation initiation factor EIF3, in cisplatin-resistant A549/DDP cells. Two circRNAs transcribed from EIF3a (circ_0004350 and circ_0092857) were validated to exhibit differential expression between A549/DDP and parental A549 cells. Moreover, downregulation of circ_0004350 and circ_0092857 reversed cisplatin resistance in lung cancer cells. Functional enrichment analysis revealed that these two circEIF3as may have a synergistic functional effect with their parental EIF3a gene on cisplatin resistance.

Circ_0076305 is another circRNA identified to promote cisplatin resistance in lung cancer. Significantly elevated expression of circ_0076305 was proven in cisplatin-resistant tissues and cells [132]. Moreover, cisplatin treatment was found to effectively upregulate the expression of circ_0076305 in A549 and H1650 cells. Further gain- and loss-of-function experiments indicated that circ_0076305 can regulate cisplatin resistance in lung cancer cells. Bioinformatic and mechanistic experiments such as circRNA immunoprecipitation (circRIP) and luciferase reporter assays were used to validate the binding of circ_0076305 to miR-296-5p as well as to miR-296-5p and STAT3. Reports have indicated that miR-296-5p acts as a tumor suppressor in lung cancer and that STAT3 can contribute to cisplatin resistance $[133,134]$. Pearson correlation analysis showed that the expression levels of circ_0076305 are negatively correlated with those of miR-296-5p and positively correlated with those of STAT3. These results suggest that circ 0076305 increases cisplatin resistance by acting as a miR-296-5p sponge to promote STAT3 expression in lung cancer. Zheng et al. [135] reported that circPVT1 contributes to cisplatin resistance in lung adenocarcinoma via the miR-145-5p/ABCC1 axis. However, 
circRNAs can also act as suppressors of cisplatin resistance in lung cancer. Circ_0001946 expression was significantly lower in A549/DDP cells than in parental A549 cells [136]. The $1485 \mathrm{nt}$ long circ_0001946 is derived from cerebellar degeneration-related protein 1 (CDR1). Knockdown of this circRNA was found to increase cisplatin resistance in A549 cells, and the results of a host cell reactivation (HCR) assay and Western blot analysis demonstrated that silencing circ_0001946 activates the nucleotide excision repair (NER) signaling pathway, which increases the ability for DNA damage repair [137], to reduce cisplatin sensitivity in lung cancer.

Treatments for osteosarcoma (OS), the most common malignant bone tumor in teenagers, are limited [138]. Cisplatin-based neoadjuvant chemotherapy has greatly improved the 5-year survival rate of OS to $70-80 \%$, but patients with resistance to cisplatin still have poor clinical outcomes [139]. Zhu et al. [140] reported dysregulation of eighty circRNAs in paired cisplatin-based chemotherapyresistant and cisplatin-based chemotherapy-sensitive OS cell lines, and bioinformatic analysis indicated that these circRNAs are significantly related to drug metabolism. In addition, the most strongly upregulated circRNA, circ 0004674, was confirmed in both tissues and cells. Patients with high circ_0004674 expression have shorter overall survival times than those with low circ_0004674 expression. These results indicate a potential crucial role of circRNAs in cisplatin-based chemotherapeutic resistance in OS. Moreover, Zhu et al. constructed competing endogenous RNA (ceRNA) networks on the basis of bioinformatic analysis combined with well-known drug resistancerelated genes and signaling pathways. The circ_0001258/ miR-744-3p/GSTM2 axis was confirmed by mechanistic studies to contribute to resistance to cisplatin-based chemotherapeutics in OS [141]. Zhang et al. [142] found that circ_001569 can promote cisplatin resistance by activating the Wnt/ $\beta$-catenin signaling pathway in OS cells. Overexpression of circPVT1 in chemo resistant OS patients has also been reported, and this pattern indicated poor prognosis [143]. In addition, serum circPVT1 expression was found to be increased in OS patients compared with healthy controls, indicating the possible clinical significance of serum circPVT1 as a biomarker in OS. The results of PCR and Western blot assays confirmed that CircPVT1 knockdown reduces the expression of ABCB1, a classical multidrug resistance-related gene [144], in cisplatin-resistant OS cells. In addition, the serum circ 0081001 level was found to be increased in OS patients and to gradually increase during treatment in OS patients who ultimately developed resistance to cisplatin-based chemotherapeutics. Dynamic monitoring of serum circ 0081001 may promptly and accurately reflect the changes in the chemo response of OS patients [145]. These results demonstrate the important role of circRNAs in resistance to cisplatin-based chemotherapeutics in OS. Serum circRNAs could be therapeutic biomarkers in OS.

Cisplatin-based chemotherapeutic regimens are also widely used for the treatment of other solid tumors, including hepatocellular cancer (HCC) [146], gastric cancer [147], bladder cancer [148], ovarian cancer [149] and thyroid cancer [150]. Luo et al. [151] identified circRNA_101505 as an inhibitor of cisplatin resistance in HCC. Low expression of circRNA_101505 was found to be correlated with cisplatin resistance and to indicate poor prognosis in HCC. Overexpression of circRNA 101505 sensitizes resistant HCC cells to cisplatin both in vitro and in vivo. NOR1 is a tumor suppressor that can inhibit cisplatin-induced autophagy, leading to increased cisplatin cytotoxicity and apoptosis in cancer [152]. Mechanistic studies demonstrated that upregulation of circRNA_101505 can promote NOR1 expression by sponging miR-103, thus reversing cisplatin resistance in HCC. In addition, both circ_0081143 and circAKT3 are upregulated in cisplatin-resistant gastric cancer. Circ_0081143 promotes CDK6 activity by sponging miR646, and circAKT3 acts as an endogenous sponge by directly binding miR-198 to upregulate PIK3R1, resulting in enhanced cisplatin resistance in gastric cancer [153, 154]. CircFN1 has also been reported to enhance cisplatin resistance by sponging miR-182-5p in gastric cancer [155]. Analysis of circRNA microarray data for cisplatin-resistant ovarian cancer tissues revealed that 339 circRNAs were aberrantly expressed with a 2 -fold change [156]. Among these circRNAs was the circRNA Cdrlas, whose downregulated expression in cisplatinresistant tissues and cells was further confirmed by qPCR. Overexpression of Cdr1as reversed the cisplatin resistance of ovarian cancer cells both in vitro and in vivo. Mechanistic studies proved that Cdr1as can function as a molecular sponge of miR-1270 to upregulate SCAI, which can promote cisplatin sensitivity in ovarian cancer. Chi et al. [157] reported that the serum circ_0000285 level was decreased in cisplatin-resistant bladder cancer patients compared to cisplatin-sensitive bladder cancer patients and that a low circ_0000285 level indicated poor prognosis, suggesting circRNA 000285 as a biomarker for the cisplatin treatment response in bladder cancer. In addition, Chen et al. [158] found that deletion of circFNTA reduces cisplatin resistance in bladder cancer. High expression of circFNTA can activate KRAS signaling via the miR-370-3p/FNTA axis, thereby contributing to cisplatin resistance.

\section{Endocrine drugs}

Endocrine therapy is the mainstay option for patients with hormone-sensitive breast and prostate cancer [159]. The androgen receptor (AR) plays a key role in the tumorigenesis of prostate cancer and is thus an effective 
therapeutic target in prostate cancer $[160,161]$. Antiandrogenic drugs such as flutamide and enzalutamide can control the progression of prostate cancer via maximal androgen blockade [162, 163]. However, the development of castration resistance is inevitable. Cao et al. [164] identified 13 circRNAs derived from AR and found overexpression of these circRNAs during progression of prostate cancer to castration-resistant prostate cancer. Moreover, these circRNAs were detectable in serum samples from castration-resistant prostate cancer patients, indicating their potential roles as biomarkers. A circRNA microarray was used to screen differentially expressed circRNA profiles in enzalutamide-resistant prostate cancer cells [165]. A total of 278 circRNAs were significantly upregulated, and 588 were downregulated. Among the downregulated circRNAs, downregulation of circ_0004870 was confirmed. Downregulated expression of this circRNA may promote the expression of AR-V7 via U2AF65 to contribute to enzalutamide resistance. Wu et al. [166] reported that circRNA17 suppression can lead to an increase in the AR-V7 level, thus leading to enzalutamide resistance. Instead of acting as a sponge, circRNA17 upregulates miR-181c-5p by maintaining its stability. MiR-181c-5p can bind the 3'-UTR of AR-V7 to decrease its expression. Functional experiments further proved that the circRNA17/miR-181c-5p/AR-v7 signaling axis alters enzalutamide resistance. CircUCK2 was also found to be downregulated in enzalutamide-resistant prostate cancer cells, indicating its role as a suppressor of enzalutamide resistance [167]. Upregulated circUCK2 can sponge miR-767-5p to upregulate TET1.

Tamoxifen (TAM) remains a cornerstone in the treatment of $\mathrm{BC}$ patients with estrogen receptor-positive tumors and has significantly improved the clinical outcome of BC patients over the past decades $[168,169]$. Resistance to TAM limits its clinical benefit. The mechanisms underlying TAM resistance are complex, and ncRNAs such as circRNAs play an important role in this process [170, 171]. Sang et al. [172] used a sequencing approach to compare the circRNA profile of the TAMresistant $\mathrm{BC}$ cell line MCF7/TR to that of its parental cell line MCF7. A total of 352 circRNAs were significantly upregulated, and 113 were downregulated. Among the downregulated circRNAs in MCF7/TR cells was circ_0025202, which was negatively correlated with tumor progression in HR-positive $\mathrm{BC}$. The results of in vitro experiments showed that circ_0025202 expression can inhibit the malignant phenotype and TAM resistance of MCF7/TR cells, and the results of the IC50 assay demonstrated that low circ_0025202 expression contributes to TAM resistance. Bioinformatic analysis indicated that circ_0025202 may act as a miRNA sponge. Further experiments proved that circ_0025202 can upregulate FOXO3a, an inhibitor of TAM resistance in $\mathrm{BC}$
[173], by sponging miR-182-5p, leading to reversion of TAM resistance. Liang et al. [174] identified a novel circRNA, circBMPR2, as a suppressor of TAM resistance in BC. Upregulated circBMPR2 can sponge miR-553 to prevent it from inhibiting the tumor suppressor USP4 [175] and mitigate TAM resistance. Thus, the circBMPR2/miR-553/USP4 axis may be a therapeutic target in TAM-resistant BC.

\section{Targeted and immunotherapeutic drugs}

Targeted therapy has been widely used in the clinic due to its excellent efficacy [176]. Small molecule inhibitors that target the epidermal growth factor receptor (EGFR) tyrosine kinase, such as gefitinib and osimertinib (AZD9291), have ushered in a new era in the treatment of NSCLC patients with activating EGFR mutations [177]. However, acquired resistance to EGFR tyrosine kinase inhibitors (EGFR-TKIs) remains inevitable [178]. Liu et al. [179] reported that circRNAs may act as predictive biomarkers for the efficacy of gefitinib therapy. A total of 1377 differentially expressed circRNAs in the plasma of patients with EGFR-mutant NSCLC were identified by microarray analysis; of these circRNAs, 989 were upregulated and 388 were downregulated. RTqPCR was used to further validate the differential expression of circ_0109320 and circ_0134501 in an independent cohort of gefitinib-treated NSCLC patients. Pearson correlation analysis indicated a positive correlation between circ_0109320 expression and progressionfree survival (PFS), and the Kaplan-Meier survival curve showed that patients with high circ_0109320 expression had longer PFS times. In addition, Zhou et al. [180] reported a novel circRNA, circ_0004015, involved in gefitinib resistance. Circ_0004015 overexpression was found to contribute to the development of gefitinib resistance in HCC827 cells. Mechanistically, circ_0004015 sponges miR-1183. PDPK1 is a classic effector of the epidermal growth factor (EGF) signaling pathway that can prevent apoptosis and mediate drug resistance in cancer [181, 182]. PDPK1 was proven to be a target gene of miR1183. Functional assays demonstrated that circ_0004015 induces gefitinib resistance via regulation of the miR$1183 /$ PDPK1 axis. Osimertinib is a third-generation EGFR-TKI that can overcome the resistance to firstgeneration EGFR-TKIs caused by the T790M mutation $[183,184]$. However, acquired resistance to osimertinib is unavoidable and lacks effective countermeasures [185]. Chen et al. [186] successfully established osimertinib-resistant NSCLC cell lines (H1975/AZDR and HCC827/AZDR) and screened these cell lines for dysregulated circRNAs. A total of 15,504 differentially expressed circRNAs were identified, of which 7966 were upregulated and 7538 were downregulated. GO and KEGG analyses of circRNA host genes indicated their 
involvement in molecular functions such as DNA replication and signaling pathways such as the p53 signaling pathway, which directly correlate with cancer pathogenesis.

Fusion between BCR (chromosome 22q11.2) and ABL1 (chromosome 9q34) leads to chronic myeloid leukemia (CML) [187]. The first human malignancy to be treated with targeted drugs, CML has an $85 \%$ survival rate with imatinib therapy [188]. However, the emergence of resistance to imatinib has become a significant problem [189]. Pan et al. [190] identified a novel circRNA, circBA9.3, derived from BCR-ABL1 in CML patients. CircBA9.3 was found to be significantly overexpressed in imatinib-resistant CML patients. Upregulation of circBA9.3 contributes to imatinib resistance by promoting the proliferation and inhibiting the apoptosis of cells. Western blot analysis results demonstrated that circBA9.3 may upregulate ABL1 and BCRABL1 protein expression to induce imatinib resistance. Ping et al. [191] found that circ_100053 is significantly upregulated in the serum of CML patients with imatinib resistance, indicating that circ_100053 may be a biomarker for imatinib resistance in CML.

Currently, immunotherapy, represented by anti-PD-1/ PD-L1 antibodies, has shown great efficacy in the clinical treatment of cancers such as melanoma [192]. The binding of PD-1 and PD-L1 can inhibit T cell activation and lead to tumor immune escape [193]. Therefore, blocking this signaling pathway with specific inhibitors can promote $\mathrm{T}$ cell recognition and killing of tumor cells [194]. Anti-PD-1/PD-L1 antibodies such as nivolumab, pembrolizumab, atezolizumab and durvalumab have been approved by the FDA for NSCLC treatment [195-197]. However, resistance to PD1/PD-L1 blockade therapy remains a major issue during treatment [198]. A retrospective analysis by Zhang et al. [199] of 20 NSCLC patients receiving anti-PD-1 antibody immunotherapy indicated that high circFGFR1 expression may contribute to resistance to anti-PD-1 agents. Further investigation proved that circFGFR1 can sponge miR-381-3p to upregulate CXCR4, which has been widely reported as an immunosuppressive element in the tumor environment to induce the exclusion of $\mathrm{T}$ lymphocyte-like $\mathrm{CD} 8+\mathrm{T}$ cells and mediate resistance to anti-PD-1 therapy [200, 201]. On the other hand, CXCR4 blockade can promote the efficacy of anti-PD-1 therapy via mobilization of CD8+ T cells [202]. In addition, a negative correlation between circFGFR1 and CXCR4 expression and CD8+ T cell frequency was discovered in 210 pairs of NSCLC and matched nontumor tissues [199].

\section{Future potential}

Cancer has become the leading cause of death worldwide. Hanahan and Weinberg proposed six basic hallmarks of cancer in 2000 [203]. These hallmarks are (1) sustaining proliferative signaling, (2) evading growth suppressors, (3) enabling replicative immortality, (4) activating invasion and metastasis, (5) inducing angiogenesis, and (6) resisting cell death. Two emerging hallmarks, reprogramming of energy metabolism and evading immune destruction, were added in 2011 [204]. A genetic imbalance underlies these hallmarks of cancer. The main cause of drug resistance is also the genetic dysregulation of cancer hallmarks. As ncRNAs dysregulation occurs in virtually all human cancers, ncRNAs are also strongly related to each cancer hallmark and subsequently contribute to drug resistance. Linear lncRNAs and miRNAs are relatively well-studied ncRNAs [205, 206]. For example, the loss of miR-7 in colorectal cancer promotes EGFR expression, the core of classic proliferative EGFR signaling pathway. Tumor proliferation increases and resistance to cetuximab, a widely used EGFR inhibitor in clinical practice, is established [207]. The lncRNA HULC triggers autophagy, a multifaceted regulator of cell death [208], by stabilizing Sirt1 and leads to chemotherapy resistance in HCC [209]. Our group also focused on ncRNA-related drug resistance [210]. As shown in our previous study, miR-224 affects the G1/S transition of the cell cycle and apoptosis by modulating the p21 (WAF1/CIP1)/pRb pathway and the intrinsic mitochondrial death pathway, thereby promoting the resistance to cisplatin in lung adenocarcinoma [211]. Moreover, the lncRNA UCA1 epigenetically silences CDKN1A expression to inhibit cell apoptosis and contributes to gefitinib resistance [212]. Compared with linear lncRNAs, circRNAs related to anticancer drug resistance have been studied relatively less frequently. Few research summaries of this topic are currently available. We propose that a review of the existing literature describing the roles of circRNAs in anticancer drug resistance will provide the direction for future circRNA research.

CircRNAs were first identified as plant viroids, yeast mitochondrial RNAs, and hepatitis $\delta$ virus genomes. They were previously considered RNA splicing errors with no biological functions because of their generally low expression and absence of protein-coding ability [213]. With the development of gene sequencing and microarray techniques, the emerging role of circRNAs in physiological and pathological conditions has been revealed in recent studies [214]. For example, circCdr1as helps maintain brain function, and animals with circCdrlas knockout display excitatory synaptic transmission-related neuropsychiatric disorders [28].

At present, the main methods for detecting and quantifying circRNAs include RNA sequencing, microarray, PCR and northern blotting [26]. RNA sequencing and microarrays are characterized by high throughput, moderate accuracy and sensitivity $[215,216]$, while PCR is characterized by low throughput, high accuracy and sensitivity [217]. RNA sequencing also has the potential to 
identify novel circRNAs [215]. Northern blotting is the least expensive technique but has low throughput, accuracy and sensitivity, and thus it is relatively unsuitable for circRNAs research. As shown in Table 2 and Fig. 2, simultaneous profiling of large numbers of anticancer drug resistance-related circRNAs might be feasible using microarray and RNA sequencing techniques. PCR, on the other hand, is mainly used to validate the differential expression of a few key circRNAs after a bioinformatics analysis of data obtained from microarrays and RNA sequencing [217]. Therefore, RNA sequencing and microarrays are currently the best options for screening circRNAs related to anticancer drug resistance.

CircRNA-induced drug resistance is not limited to traditional chemotherapeutic drugs, advanced targeted drugs and immunotherapeutic drugs are also affected (Tables 3, 4 and 5). Moreover, circRNA-related drug resistance affects a wide range of cancer types. These observations demonstrate the ubiquity of circRNAs in mediating anticancer drug resistance. In addition, although most circRNAs mediate drug resistance by acting as sponges, other molecular mechanisms have also been reported, such as maintaining the stability of downstream miRNAs [166]. Common mechanisms underlying drug resistance include DNA repair, abnormal activation of signaling pathways, cancer stemness and the EMT [218]. A primary action of chemotherapy is to mediate DNA damage in cells, which in turn induces cancer cell death. In contrast, DNA repair determines the ability of cells to resist drugs. The NER pathway is essential for repairing DNA cross-linking damage caused by chemotherapeutic drugs such as cisplatin [219]. The deletion of circ_0001946 might activate the NER pathway to increase DNA repair, leading to cisplatin resistance in A549/DDP cells [136]. Abnormal activation of oncogenic signaling pathways inhibits drug-mediated cell death by transmitting bypass or downstream signals. AKT, a dominant effector of PI3K signaling, induces cell survival and proliferation by regulating the expression of genes with antiapoptotic activity, such as CREB and NF-kB [220]. CircAMOTL1 increases the levels of the both phosphorylated and total AKT proteins to induce taxol resistance in BC [100]. The Wnt/ $\beta$-catenin signaling pathway is another classic resistance-related pathway [221]. Its activation by circ_001569 also contributes to cisplatin resistance in OS [142]. Cancer stem cells (CSCs) have been regarded as "tumor-initiating cells". Since the recognition of cancer heterogeneity, CSCs, a small proportion of cancer cells, were considered to contribute to therapy resistance [222]. Circ_001680 upregulates BMI1, a positive regulator of stem cell-like properties, by targeting miR-340. A flow cytometry-based analysis further confirmed that the circ_001680/miR-340/BMI1 axis increases the CSC population, resulting in metastasis and irinotecan resistance in CRC [59]. The EMT is referred as a type of cellular reprogramming from the epithelial to mesenchymal-like phenotype. Morphological changes have been observed during the EMT process. This change has also become an obstacle to therapy [223]. CircRNAs are also involved in EMT-mediated resistance. CircCRIM1 promotes NPC metastasis and docetaxel resistance by upregulating FOXQ1 to enhance the EMT [111].

Notably, the EMT and CSCs have been recognized as participating in the strong crosstalk between drug resistance and metastasis [224, 225]. Most cancer-related deaths are caused by metastasis, particularly in patients presenting drug resistance and tumor recurrence [224]. Obviously, the circRNA-related drug resistance mechanism not only mediates drug resistance but also promotes metastasis. As another example, the circRNA UCK2 simultaneously inhibits invasion and enzalutamide resistance by upregulating TET1 in prostate cancer [167]. TET1 is an important regulator of both cancer stemness and the EMT [226]. The molecular mechanisms of drug resistance regulated by circRNAs exhibit crosstalk with each other, which also lead to complex crosstalk between various malignant phenotypes, such as drug resistance and metastasis. Our understanding of the molecular mechanisms of circRNAs in tumor resistance is still very superficial. CircRNAs undoubtedly play an important role in anticancer drug resistance, and further studies are urgently needed.

CircRNAs are abundantly expressed and may be specifically expressed in a cell- and tissue-specific manner. They also play important biological roles in tumor resistance through various molecular mechanisms. Therefore, the detection of circRNAs in clinical samples may have implications for clinical diagnosis and treatment; in other words, they have the potential to serve as biomarkers. The unique closed loop structure of circRNAs increases their stability in body fluids and blood [227]. Liquid biopsy, a minimally invasive method for analyzing liquid specimens obtained from patients, has been widely used in cancer biomarker detection. Liquid biopsies of typical biomarkers such as cell-free DNA (cfDNA) can provide effective information on tumor diagnosis and treatment [228]. The unique closed loop structure of circRNAs increases their stability in body fluids; thus, circRNAs are a good biomarker for investigation via liquid biopsies [227]. For example, the level of the circRNA FECR1 is aberrantly increased in serum exosomes of small cell lung cancer (SCLC) patients and is associated with the chemotherapeutic response [229]. As mentioned above, 13 circRNAs overexpressed during the progression of PC to castration-resistant PC were detectable in serum samples from patients with castrationresistant PC [164]. Downregulated serum circ_0000285 
Table 2 Microarray and RNA sequencing of dysregulated circRNAs in anticancer drug resistance

\begin{tabular}{|c|c|c|c|c|c|c|c|c|}
\hline \multirow[t]{2}{*}{ Cancer } & \multirow[t]{2}{*}{ Drug classes } & \multirow[t]{2}{*}{ Drug } & \multirow[t]{2}{*}{ Specimen } & \multirow[t]{2}{*}{ Methods } & \multicolumn{2}{|l|}{ DEGs } & \multirow[t]{2}{*}{ Bioinformation analysis } & \multirow[t]{2}{*}{ Ref } \\
\hline & & & & & UP & Down & & \\
\hline $\begin{array}{l}\text { Prostate } \\
\text { Cancer }\end{array}$ & $\begin{array}{l}\text { Endocrine } \\
\text { drugs }\end{array}$ & Enzalutamide & $\begin{array}{l}\text { Enzalutamide } \\
\text { resistance LNCaP } \\
\text { cell models }\end{array}$ & Microarray & 278 & 588 & NA & [165] \\
\hline \multirow[t]{2}{*}{ Breast Cancer } & & Tamoxifen & $\begin{array}{l}\text { MCF7/TR and } \\
\text { MCF7/P cells }\end{array}$ & $\begin{array}{l}\text { RNA } \\
\text { sequencing }\end{array}$ & 352 & 113 & NA & [172] \\
\hline & $\begin{array}{l}\text { Anticancer } \\
\text { antibiotics }\end{array}$ & Doxorubicin & $\begin{array}{l}\text { MCF-7 and MCF-7/ } \\
\text { ADM cells }\end{array}$ & Microarray & 12 & 6 & MAPK and PI3K/Akt signaling pathway; & [117] \\
\hline $\begin{array}{l}\text { Acute } \\
\text { Myeloid } \\
\text { Leukemia }\end{array}$ & & & $\begin{array}{l}\text { THP-1 and THP-1/ } \\
\text { ADM cells }\end{array}$ & Microarray & 35 & 14 & NA & [114] \\
\hline \multirow[t]{2}{*}{$\begin{array}{l}\text { Pancreatic } \\
\text { Cancer }\end{array}$} & $\begin{array}{l}\text { Antimetabolite } \\
\text { drugs }\end{array}$ & Gemcitabine & $\begin{array}{l}\text { SWI990 and } \\
\text { SWI990/GZ cells }\end{array}$ & Microarray & 26 & 55 & MAPK and mTOR signaling pathways; & [80] \\
\hline & & & $\begin{array}{l}\text { PANC-1 and PANC- } \\
1-\text { GR cells }\end{array}$ & $\begin{array}{l}\text { RNA } \\
\text { sequencing }\end{array}$ & 68 & 58 & ErbB pathway; & [83] \\
\hline \multirow[t]{3}{*}{$\begin{array}{l}\text { Colorectal } \\
\text { Cancer }\end{array}$} & & $5-\mathrm{FU}$ & $\begin{array}{l}\text { HCT116 and CRR- } \\
\text { HCT116 cells }\end{array}$ & Microarray & 47 & 24 & Wnt signaling pathway; & [72] \\
\hline & Platinum drugs & Oxaliplatin & $\begin{array}{l}\text { HCT116-P (parental) } \\
\text { and HCT116-R cells }\end{array}$ & Microarray & 773 & 732 & Protein-binding activity; & [126] \\
\hline & & & $\begin{array}{l}\text { Exosomes from } \\
\text { HCT116-P (parental) } \\
\text { and HCT116-R cells }\end{array}$ & Microarray & 105 & 34 & $\begin{array}{l}\text { Longevity regulating pathway; Wnt signaling } \\
\text { pathway; cGMP-PKG signaling pathway; }\end{array}$ & [127] \\
\hline Osteosarcoma & & Cisplatin & $\begin{array}{l}\text { Paired resistant and } \\
\text { sensitive OS cell } \\
\text { lines (MG63, KHOS } \\
\text { and U2OS) }\end{array}$ & $\begin{array}{l}\text { RNA } \\
\text { sequencing }\end{array}$ & 57 & 23 & $\begin{array}{l}\text { Glycosphingolipid biosynthesis-globo series; } \\
\text { Linoleic acid metabolism; }\end{array}$ & [140] \\
\hline \multirow[t]{2}{*}{$\begin{array}{l}\text { Ovarian } \\
\text { Cancer }\end{array}$} & & & $\begin{array}{l}\text { Cisplatin-sensitive } \\
\text { and cisplatin- } \\
\text { resistant tissues }\end{array}$ & Microarray & 148 & 191 & NA & [156] \\
\hline & $\begin{array}{l}\text { Drugs derived } \\
\text { from plants }\end{array}$ & Taxol & $\begin{array}{l}\text { Taxol-sensitive and } \\
\text { Taxol-resistant ovar- } \\
\text { ian cancer tissues }\end{array}$ & Microarray & 341 & 492 & NA & [98] \\
\hline \multirow[t]{3}{*}{ NSCLC } & & & $\begin{array}{l}\text { A549 and A549/ } \\
\text { Taxol cells }\end{array}$ & Microarray & 2909 & 8372 & $\begin{array}{l}\text { Small GTPase binding; Integrin signaling } \\
\text { pathway; }\end{array}$ & [101] \\
\hline & Targeted drug & Gefitinib & Plasma samples & Microarray & 989 & 388 & $\begin{array}{l}\text { Biological processes of various cancers such } \\
\text { as cancers of hematopoietic and lymphoid } \\
\text { tissues, bladder cancer, colorectal cancer, } \\
\text { and neuroblastoma; }\end{array}$ & [179] \\
\hline & & Osimertinib & $\begin{array}{l}\text { H1975/AZDR and } \\
\text { H1975; HCC827/ } \\
\text { AZDR and HCC827; }\end{array}$ & Microarray & 7966 & 7538 & $\begin{array}{l}\text { P53, mTOR, and focal adhesion signaling } \\
\text { pathways; }\end{array}$ & [186] \\
\hline
\end{tabular}

Ref Reference

indicates cisplatin resistance in bladder cancer [157]. Collectively, circRNAs represent potential biomarkers related to resistance to anticancer drugs in clinical applications. Dynamic monitoring is a promising strategy to comprehensively assess the cancer status and therapeutic response [230]. Notably, the serum circ_0081001 level gradually increases in patients with OS during treatment with cisplatin-based chemotherapy, indicating the potential of circRNAs in dynamic monitoring [145]. With the discovery of increasing numbers of circRNAs with the potential to serve as biomarkers, we must comprehensively consider the sensitivity and specificity of these serum circRNAs for monitoring drug resistance to select the most suitable candidate molecules.

In recent years, the development of effective therapies to regulate ncRNAs has been an active area of investigation. Hundreds of clinical trials involving ncRNAs are already underway [19]. For example, mimics of miR-34, a tumor suppressor miRNA, have reached phase I clinical trials [231]. The most classic components of RNA drugs are oligonucleotides that specifically targeting the ncRNA and transporters used for transport and maintenance of stability. Studies of circRNAs are still in the early stages, and we still lack the technology to safely 


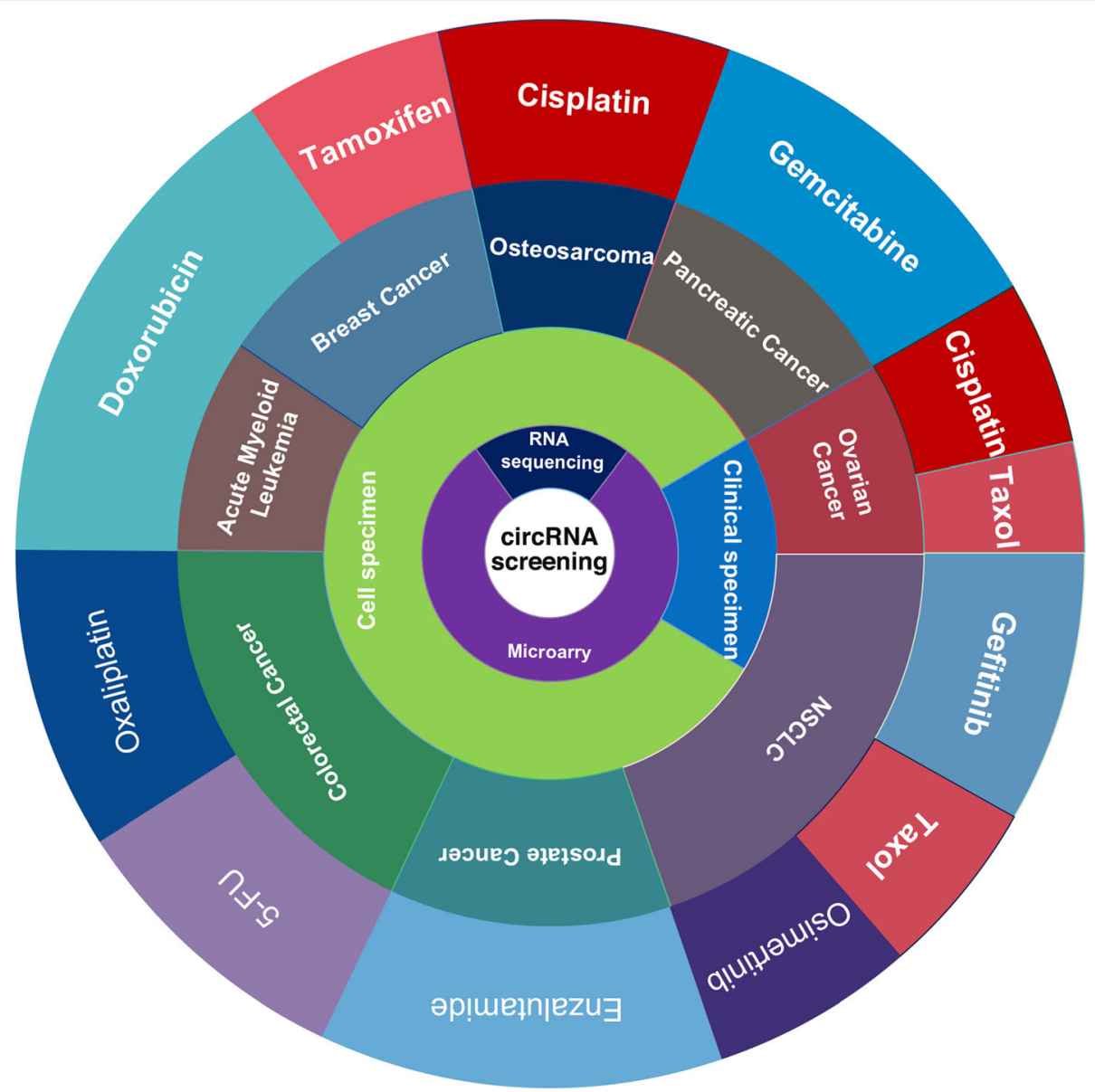

Fig. 2 RNA sequencing and microarray analyses are effective methods to screen novel anticancer drug resistance-related circRNAs

and effectively regulate circRNAs in the human body. To date, no preclinical trials of circRNAs for cancer treatment have been reported [232]. However, some features of circRNAs make them worth exploring as potential therapeutic targets.

On one hand, circRNAs are potentially useful as direct therapeutic targets by modulating their expression. Some of the main oncogenic circRNAs are abnormally expressed in a variety of tumors and are associated with multidrug resistance. Precise regulation of these oncogenic circRNAs may exert a therapeutic effect on more malignant tumors. The unique back splice junction of circRNAs represents a potentially specific therapeutic target because it distinguishes circRNAs from the linear RNAs transcribed from the same genes. In other words, we will be able to more precisely regulate these oncogenic circRNAs without affecting functions of normal linear RNAs. For example, as described above, circPVT1 is upregulated in gastric cancer, NSCLC and osteosarcoma. This upregulation leads to multidrug resistance, including Taxol, oxaliplatin and cisplatin [92, 135, 143]. Precise circPVT1-specific RNA drugs may have potential applications in treating multidrug resistance in all these tumors. On the other hand, because of their stability and their multiple binding sites for miRNAs, tumor suppressor circRNAs are potential therapeutic sponge vectors [27]. For example, circ_0002483 might sponge miR-182$5 p$ to increase Taxol sensitivity in patients with NSCLC [106]. CircRNA_101505 alleviates cisplatin resistance in HCC by sponging miR-103 [151]. The sponging capacity of tumor suppressor circRNAs might be used to specifically design and target specific oncogenic miRNA profiles, subsequently exerting a therapeutic effect. A major challenge to the implementation of any of the aforementioned strategies will be accurately transport into the malignant cells to avoid side effects on normal cells.

\section{Conclusion}

In summary, circRNAs have been thoroughly proven to participate in anticancer drug resistance. We reviewed 
Table 3 CircRNAs in non-platinum cytotoxic drugs

\begin{tabular}{|c|c|c|c|c|c|c|}
\hline $\begin{array}{l}\text { Cell cycle } \\
\text { specificity }\end{array}$ & Drug & Cancer & CircRNAs & Mechanism & Role & Ref \\
\hline \multirow[t]{4}{*}{ S phase } & Irinotecan & Colorectal Cancer & circ_001680 & MiR-340/BMl1 axis & Up & [59] \\
\hline & Pemetrexed & Gastric Cancer & circMTHFD2 & MiR-124/ FDZ5/MDR-1 axis & Up & [66] \\
\hline & Gemcitabine & Renal Cancer & circ_0035483 & MiR-335/CCNB1 axis & Up & [76] \\
\hline & & Pancreatic Cancer & $\begin{array}{l}\text { chr14:101402109-101,464,448+; chr4: } \\
\text { 52729603-52,780,244+; }\end{array}$ & Downregulate miR-145-5p & Up & [83] \\
\hline \multirow[t]{6}{*}{ M phase } & Taxol & Gastric cancer & circPVT1 & MiR-124-3p/ZEB1 axis & Up & [92] \\
\hline & & Ovarian Cancer & circ_0063809 & MiR-1252/ FOXR2 axis & Up & [98] \\
\hline & & Breast Cancer & circAMOTL1 & Activating AKT pathway & Up & [100] \\
\hline & & NSCLC & circ_0002483 & $\begin{array}{l}\text { MiR-182-5p/GRB2/FOXO1/ } \\
\text { FOXO3 axis }\end{array}$ & Down & [106] \\
\hline & Docetaxel & $\begin{array}{l}\text { Lung } \\
\text { Adenocarcinoma }\end{array}$ & circ_0003998 & Downregulate miR-326 & Up & [107] \\
\hline & & $\begin{array}{l}\text { Nasopharyngeal } \\
\text { Carcinoma }\end{array}$ & circCRIM1 & MiR-422a/FOXQ1 axis & Up & [1111] \\
\hline \multirow[t]{3}{*}{$\begin{array}{l}\text { Cell cycle- } \\
\text { nonspecific }\end{array}$} & Doxorubicin & $\begin{array}{l}\text { Acute Myeloid } \\
\text { Leukemia }\end{array}$ & circPAN3 & $\begin{array}{l}\text { MiR-153-5p/miR-183-5p/XIAP } \\
\text { axis }\end{array}$ & Up & [114] \\
\hline & & Breast Cancer & circ_0006528 & MiR-7-5p/ Raf1 axis & Up & [117] \\
\hline & & & circKDM4C & MiR-548p/ PBLD axis & Down & [122] \\
\hline
\end{tabular}

Ref Reference

Table 4 CircRNAs in platinum drugs

\begin{tabular}{|c|c|c|c|c|c|}
\hline Drug & Cancer & CircRNAs & Mechanism & Role & Ref \\
\hline \multirow[t]{3}{*}{ Oxaliplatin } & Colorectal Cancer & circ_032883 & Sponge miR-501-5p & Up & {$[126]$} \\
\hline & & circ_0338 & NA & Up & [127] \\
\hline & & circ_0005963 & MiR-122/PKM2 axis & Up & [128] \\
\hline \multirow[t]{16}{*}{ Cisplatin } & NSCLC & circ_0004350; circ_0092857 & Synergy effect with the parental EIF3a gene & Up & [131] \\
\hline & & circ_0076305 & MiR-296-5p/STAT3 axis & Up & [132] \\
\hline & & circPVT1 & MiR-145-5p/ABCC1 axis & Up & [135] \\
\hline & & circ_0001946 & Activating the NER signaling pathway to increased DNA repair ability & UP & [136] \\
\hline & Osteosarcoma & circ_0004674 & NA & Up & [140] \\
\hline & & circ_0001258 & MiR-744-3p/GSTM2 axis & Up & [141] \\
\hline & & circ_001569 & Activating Wnt/ß-catenin signaling pathway & Up & [142] \\
\hline & & circPVT1 & Upregulate ABCB1 & Up & [143] \\
\hline & & circ_0081001 & NA & Up & [145] \\
\hline & Hepatocellular Cancer & circRNA_101505 & MiR-103/NOR1 axis & Down & [151] \\
\hline & Gastric Cancer & circ_0081143 & MiR-646/CDK6 axis & Up & [154] \\
\hline & & circAKT3 & MiR-198/ PIK3R1 axis & Up & [153] \\
\hline & & circFN1 & Sponging miR-182-5p & Up & [155] \\
\hline & Ovarian Cancer & Cdr1as & MiR-1270/SCAl axis & Down & [156] \\
\hline & Bladder Cancer & circ_000285 & NA & Down & [157] \\
\hline & & circFNTA & MiR-370-3p/FNTA axis & Up & [158] \\
\hline
\end{tabular}


Table 5 CircRNAs in other drugs

\begin{tabular}{|c|c|c|c|c|c|c|}
\hline Classification & Drug & Cancer & CircRNAs & Mechanism & Role & Ref \\
\hline \multirow[t]{5}{*}{ Endocrine Drugs } & Enzalutamide & Prostate Cancer & circ_0004870 & U2AF65/AR-V7 axis & Down & [165] \\
\hline & & & circRNA17 & Maintaining stability of miR-181c-5p & Down & [166] \\
\hline & & & circUCK2 & MiR-767-5p/TET1 axis & Down & [167] \\
\hline & Tamoxifen & Breast Cancer & circ_0025202 & MiR-182-5p/FOXO3a axis & Down & [172] \\
\hline & & & $\operatorname{circBMPR2}$ & MiR-553/USP4 axis & Down & [174] \\
\hline \multirow[t]{4}{*}{ Targeted drugs } & Gefitinib & NSCLC & circ_0109320 & NA & Down & [179] \\
\hline & & & circ_0004015 & MiR-1183/PDPK1 axis & Up & [180] \\
\hline & Imatinib & Chronic Myeloid Leukemia & circBA9.3 & Upregulate the ABL1 and BCRABL1 protein expression & Up & [190] \\
\hline & & & circ_100053 & NA & Up & [191] \\
\hline Immune drugs & PD-1 inhibitor & NSCLC & circFGFR1 & MiR-381-3p/CXCR4 axis & Up & [199] \\
\hline
\end{tabular}

Ref Reference

the functions of circRNAs and potential mechanisms by which these circRNAs regulate resistance depending on the classification of anticancer drugs. These circRNAs have great potential in monitoring and overcoming anticancer drug resistance, and many circRNAs that are deeply involved in drug resistance remain unknown. Further investigation of these resistance-related circRNAs will expand their clinical potential.

\section{Abbreviations}

ncRNA: noncoding RNAs; circRNAs: circular RNAs; EcircRNAs: Exonic circRNAs; ciRNAs: intronic circRNAs; ElciRNAs: Exon-intron circRNAs; CRC: Colorectal cancer; 5-FU: 5-Fluorouracil; PC: Pancreatic cancer; GO: Gene ontology; BC: Breast cancer; NSCLC: Non-small cell lung cancer; 3'-UTRs: 3' untranslated regions; Circlnteractome: Circular RNA Interactome; NPC: Nasopharyngeal carcinoma; AML: Acute myeloid leukemia; KEGG: Kyoto Encyclopedia of Genes and Genomes; PBLD: Phenazine biosynthesis-like domain-containing protein; DACH: (1R,2R)-1,2-diaminocyclohexane; circRIP: circRNA immunoprecipitation; CDR1: Cerebellar degeneration-related protein 1; HCR: Host cell reactivation; NER: Nucleotide excision repair;

OS: Osteosarcoma; ceRNA: competing endogenous RNA; HCC: Hepatocellular cancer; AR: Androgen receptor; TAM: Tamoxifen; EGFR: Epidermal growth factor receptor; EGFR-TKIs: EGFR tyrosine kinase inhibitors; PFS: Progressionfree survival; EGF: Epidermal growth factor; CML: Chronic myeloid leukemia; cfDNA: cell-free DNA; SCLC: Small cell lung cancer; EMT: Epithelialmesenchymal transition; CSCs: Cancer stem cells

\section{Acknowledgements}

Not applicable.

\section{Authors' contributions}

ZW and CW conceived the structure of manuscript and revised the manuscript. LW and QC made the figures and tables. TX, MW, LJ and LM drafted initial manuscript. All authors read and approved the final manuscript.

\section{Funding}

This work was supported by grants from the National Natural Science Foundation of China (No. 81871871, 81703056, 81802275, 81702260;), Key Research and Development plan (Social development) of science and technology department of Jiangsu Province (No.BE2019760). the Medical Innovation Team Foundation of the Jiangsu Provincial Enhancement Health Project (No. CXTDA2017021), Project 789 of Excellent Talent Training Program of The Second Affiliated Hospital of Nanjing Medical University (No.789ZYRC202090148)

Availability of data and materials Not applicable.
Ethics approval and consent to participate

Not applicable.

\section{Consent for publication}

Not applicable.

\section{Competing interests}

The authors declare that they have no competing interests.

\section{Author details}

${ }^{1}$ Cancer Medical Center, The Second Affiliated Hospital of Nanjing Medical University, Jiangjiayuan road 121\#, Nanjing 210011, Jiangsu, P.R. China. 2Department of Oncology, The Affiliated Huai'an No.1 People's Hospital of Nanjing Medical University, Huai'an 223300, Jiangsu, China.

Received: 11 May 2020 Accepted: 31 July 2020

Published online: 17 August 2020

\section{References}

1. Siegel RL, Miller KD, Jemal A. Cancer statistics, 2019. CA Cancer J Clin. 2019; 69:7-34.

2. Hamilton W, Walter FM, Rubin G, Neal RD. Improving early diagnosis of symptomatic cancer. Nat Rev Clin Oncol. 2016;13:740-9.

3. Thompson WO. Uses and abuses of the male sex hormone. J Am Med Assoc. 1946;132:185-8.

4. Ke EE, Wu YL. EGFR as a Pharmacological Target in EGFR-Mutant Non-SmallCell Lung Cancer: Where Do We Stand Now? Trends Pharmacol Sci. 2016;37: 887-903.

5. Akinleye A, Rasool Z. Immune checkpoint inhibitors of PD-L1 as cancer therapeutics. J Hematol Oncol. 2019;12:92.

6. Vasan N, Baselga J, Hyman DM. A view on drug resistance in cancer. Nature. 2019:575:299-309.

7. Alexandrov LB, Nik-Zainal S, Wedge DC, Aparicio SA, Behjati S, Biankin AV, Bignell GR, Bolli N, Borg A, Borresen-Dale AL, et al. Signatures of mutational processes in human cancer. Nature. 2013;500:415-21.

8. Twomey JD, Brahme NN, Zhang B. Drug-biomarker co-development in oncology - 20 years and counting. Drug Resist Updat. 2017;30:48-62.

9. Djebali S, Davis CA, Merkel A, Dobin A, Lassmann T, Mortazavi A, Tanzer A, Lagarde J, Lin W, Schlesinger F, et al. Landscape of transcription in human cells. Nature. 2012;489:101-8.

10. Mattick JS, Makunin IV: Non-coding RNA. Hum Mol Genet 2006, 15(Spec No 1):R17-R29.

11. Adams BD, Parsons C, Walker L, Zhang WC, Slack FJ. Targeting noncoding RNAs in disease. J Clin Invest. 2017:127:761-71.

12. Anastasiadou $E$, Jacob LS, Slack FJ. Non-coding RNA networks in cancer. Nat Rev Cancer. 2018;18:5-18.

13. Liu ZL, Wang H, Liu J, Wang ZX. MicroRNA-21 (miR-21) expression promotes growth, metastasis, and chemo- or radioresistance in non-small cell lung cancer cells by targeting PTEN. Mol Cell Biochem. 2013;372:35-45. 
14. Pfeffer SR, Yang CH, Pfeffer LM. The Role of miR-21 in Cancer. Drug Dev Res. 2015;76:270-7.

15. Wang ZX, Bian HB, Wang JR, Cheng ZX, Wang KM, De W. Prognostic significance of serum miRNA-21 expression in human non-small cell lung cancer. J Surg Oncol. 2011;104:847-51.

16. Slabakova E, Culig Z, Remsik J, Soucek K. Alternative mechanisms of miR-34a regulation in cancer. Cell Death Dis. 2017:8:e3100.

17. Qu X, Alsager S, Zhuo Y, Shan B. HOX transcript antisense RNA (HOTAIR) in cancer. Cancer Lett. 2019;454:90-7.

18. Ghafouri-Fard S, Taheri M. Maternally expressed gene 3 (MEG3): A tumor suppressor long non coding RNA. Biomed Pharmacother. 2019;118:109129.

19. Slack FJ, Chinnaiyan AM. The Role of Non-coding RNAs in Oncology. Cell. 2019;179:1033-55.

20. Shang $Q$, Yang Z, Jia R, Ge S. The novel roles of circRNAs in human cancer Mol Cancer. 2019:18:6.

21. Jeck WR, Sharpless NE. Detecting and characterizing circular RNAs. Nat Biotechnol. 2014;32:453-61.

22. Wang $Y$, Mo Y, Gong Z, Yang X, Yang M, Zhang S, Xiong F, Xiang B, Zhou M, Liao Q, et al. Circular RNAs in human cancer. Mol Cancer. 2017:16:25.

23. Salzman J, Chen RE, Olsen MN, Wang PL, Brown PO. Cell-type specific features of circular RNA expression. PLoS Genet. 2013;9:e1003777.

24. Maass PG, Glazar P, Memczak S, Dittmar G, Hollfinger I, Schreyer L, Sauer AV, Toka O, Aiuti A, Luft FC, Rajewsky N. A map of human circular RNAs in clinically relevant tissues. J Mol Med (Berl). 2017;95:1179-89.

25. Cui X, Wang J, Guo Z, Li M, Li M, Liu S, Liu H, Li W, Yin X, Tao J, Xu W. Emerging function and potential diagnostic value of circular RNAs in cancer. Mol Cancer. 2018;17:123.

26. Kristensen LS, Andersen MS, Stagsted LWW, Ebbesen KK, Hansen TB, Kjems J. The biogenesis, biology and characterization of circular RNAs. Nat Rev Genet. 2019:20:675-91.

27. Kristensen LS, Hansen TB, Veno MT, Kjems J. Circular RNAs in cancer: opportunities and challenges in the field. Oncogene. 2018;37:555-65.

28. Piwecka M, Glazar P, Hernandez-Miranda LR, Memczak S, Wolf SA, RybakWolf A, Filipchyk A, Klironomos F, Cerda Jara CA, Fenske P, et al. Loss of a mammalian circular RNA locus causes miRNA deregulation and affects brain function. Science. 2017;357:eaam8526.

29. Nan A, Chen L, Zhang N, Jia Y, Li X, Zhou H, Ling Y, Wang Z, Yang C, Liu S, Jiang Y. Circular RNA circNOL10 Inhibits Lung Cancer Development by Promoting SCLM1-Mediated Transcriptional Regulation of the Humanin Polypeptide Family. Adv Sci (Weinh). 2019;6:1800654.

30. Li X, Wang J, Zhang C, Lin C, Zhang J, Zhang W, Zhang W, Lu Y, Zheng L, Li $X$. Circular RNA circITGA7 inhibits colorectal cancer growth and metastasis by modulating the Ras pathway and upregulating transcription of its host gene ITGA7. J Pathol. 2018;246:166-79.

31. Chen N, Zhao G, Yan X, Lv Z, Yin H, Zhang S, Song W, Li X, Li L, Du Z, et al. A novel FLI1 exonic circular RNA promotes metastasis in breast cancer by coordinately regulating TET1 and DNMT1. Genome Biol. 2018;19:218.

32. Qin S, Zhao Y, Lim G, Lin H, Zhang X, Zhang X. Circular RNA PVT1 acts as a competing endogenous RNA for miR-497 in promoting non-small cell lung cancer progression. Biomed Pharmacother. 2019;111:244-50.

33. Zhao F, Han Y, Liu Z, Zhao Z, Li Z, Jia K. circFADS2 regulates lung cancer cells proliferation and invasion via acting as a sponge of miR-498. Biosci Rep. 2018;38:BSR20180570.

34. Wei S, Zheng Y, Jiang Y, Li X, Geng J, Shen Y, Li Q, Wang X, Zhao C, Chen Y, et al. The circRNA circPTPRA suppresses epithelial-mesenchymal transitioning and metastasis of NSCLC cells by sponging miR-96-5p. EBioMedicine. 2019:44:182-93.

35. Cheng J, Zhuo H, Xu M, Wang L, Xu H, Peng J, Hou J, Lin L, Cai J. Regulatory network of circRNA-miRNA-mRNA contributes to the histological classification and disease progression in gastric cancer. J Transl Med. 2018; $16: 216$.

36. Liu WG, Xu Q. Upregulation of circHIPK3 promotes the progression of gastric cancer via Wnt/beta-catenin pathway and indicates a poor prognosis. Eur Rev Med Pharmacol Sci. 2019:23:7905-12.

37. Chen J, Li Y, Zheng Q, Bao C, He J, Chen B, Lyu D, Zheng B, Xu Y, Long Z, et al. Circular RNA profile identifies circPVT1 as a proliferative factor and prognostic marker in gastric cancer. Cancer Lett. 2017;388:208-19.

38. Zhang J, Liu H, Hou L, Wang G, Zhang R, Huang Y, Chen X, Zhu J. Circular RNA_LARP4 inhibits cell proliferation and invasion of gastric cancer by sponging miR-424-5p and regulating LATS1 expression. Mol Cancer. 2017; 16:151.
39. Zeng K, Chen X, Xu M, Liu X, Hu X, Xu T, Sun H, Pan Y, He B, Wang S. CircHIPK3 promotes colorectal cancer growth and metastasis by sponging miR-7. Cell Death Dis. 2018;9:417.

40. Lu C, Jiang W, Hui B, Rong D, Fu K, Dong C, Tang W, Cao H. The circ_ 0021977/miR-10b-5p/P21 and P53 regulatory axis suppresses proliferation, migration, and invasion in colorectal cancer. J Cell Physiol. 2020;235:227385.

41. Chen G, Shi Y, Liu M. Sun J: circHIPK3 regulates cell proliferation and migration by sponging miR-124 and regulating AQP3 expression in hepatocellular carcinoma. Cell Death Dis. 2018;9:175.

42. Su Y, Xu C, Liu Y, Hu Y, Wu H. Circular RNA hsa_circ_0001649 inhibits hepatocellular carcinoma progression via multiple miRNAs sponge. Aging (Albany NY). 2019;11:3362-75.

43. Li Y, Zheng F, Xiao X, Xie F, Tao D, Huang C, Liu D, Wang M, Wang L, Zeng F, Jiang G. CircHIPK3 sponges miR-558 to suppress heparanase expression in bladder cancer cells. EMBO Rep. 2017;18:1646-59.

44. Ding L, Zhao Y, Dang S, Wang Y, Li X, Yu X, Li Z, Wei J, Liu M, Li G. Circular RNA circ-DONSON facilitates gastric cancer growth and invasion via NURF complex dependent activation of transcription factor SOX4. Mol Cancer. 2019;18:45.

45. Chen Y, Yang F, Fang E, Xiao W, Mei H, Li H, Li D, Song H, Wang J, Hong M, et al. Circular RNA circAGO2 drives cancer progression through facilitating HuR-repressed functions of AGO2-miRNA complexes. Cell Death Differ. 2019;26:1346-64.

46. Zhang M, Huang N, Yang X, Luo J, Yan S, Xiao F, Chen W, Gao X, Zhao K, Zhou $H$, et al. A novel protein encoded by the circular form of the SHPRH gene suppresses glioma tumorigenesis. Oncogene. 2018;37:1805-14.

47. Yang Y, Gao X, Zhang M, Yan S, Sun C, Xiao F, Huang N, Yang X, Zhao K, Zhou H, et al. Novel Role of FBXW7 Circular RNA in Repressing Glioma Tumorigenesis. J Natl Cancer Inst. 2018;110:304-15.

48. Su M, Xiao Y, Ma J, Tang Y, Tian B, Zhang Y, Li X, Wu Z, Yang D, Zhou Y, et al. Circular RNAs in Cancer: emerging functions in hallmarks, stemness, resistance and roles as potential biomarkers. Mol Cancer. 2019;18:90.

49. van Putten LM. Are cell kinetic data relevant for the design of tumour chemotherapy schedules? Cell Tissue Kinet. 1974;7:493-504.

50. Tannock I. Cell kinetics and chemotherapy: a critical review. Cancer Treat Rep. 1978;62:1117-33.

51. Gerrits CJ, de Jonge MJ, Schellens JH, Stoter G, Verweij J. Topoisomerase I inhibitors: the relevance of prolonged exposure for present clinical development. Br J Cancer. 1997;76:952-62.

52. Rebucci M, Michiels C. Molecular aspects of cancer cell resistance to chemotherapy. Biochem Pharmacol. 2013;85:1219-26.

53. Gezici S, Sekeroglu N. Current Perspectives in the Application of Medicinal Plants Against Cancer: Novel Therapeutic Agents. Anti Cancer Agents Med Chem. 2019;19:101-11.

54. Baxter-Holland M, Dass CR. Doxorubicin, mesenchymal stem cell toxicity and antitumour activity: implications for clinical use. J Pharm Pharmacol. 2018;70:320-7.

55. Roca J. The mechanisms of DNA topoisomerases. Trends Biochem Sci. 1995; 20:156-60.

56. Hsiang YH, Liu LF. Identification of mammalian DNA topoisomerase I as an intracellular target of the anticancer drug camptothecin. Cancer Res. 1988; 48:1722-6.

57. Fujita K, Kubota Y, Ishida H, Sasaki Y. Irinotecan, a key chemotherapeutic drug for metastatic colorectal cancer. World J Gastroenterol. 2015;21:1223412,248 .

58. Xu Y, Villalona-Calero MA. Irinotecan: mechanisms of tumor resistance and novel strategies for modulating its activity. Ann Oncol. 2002;13:1841-51.

59. Jian X, He H, Zhu J, Zhang Q, Zheng Z, Liang X, Chen L, Yang M, Peng K, Zhang Z, et al. Hsa_circ_001680 affects the proliferation and migration of CRC and mediates its chemoresistance by regulating BMI1 through miR340. Mol Cancer. 2020;19:20

60. Wang X, Wang C, Zhang X, Hua R, Gan L, Huang M, Zhao L, Ni S, Guo W. Bmi-1 regulates stem cell-like properties of gastric cancer cells via modulating miRNAs. J Hematol Oncol. 2016;9:90

61. Lukacs RU, Memarzadeh S, Wu H, Witte ON. Bmi-1 is a crucial regulator of prostate stem cell self-renewal and malignant transformation. Cell Stem Cell. 2010;7:682-93.

62. Su P, Yang $Y$, Wang $G$, Chen $X$, Ju $Y$. Curcumin attenuates resistance to irinotecan via induction of apoptosis of cancer stem cells in chemoresistant colon cancer cells. Int J Oncol. 2018;53:1343-53. 
63. Yang Y, Wang G, Zhu D, Huang Y, Luo Y, Su P, Chen X, Wang Q. Epithelialmesenchymal transition and cancer stem cell-like phenotype induced by Twist1 contribute to acquired resistance to irinotecan in colon cancer. Int J Oncol. 2017:51:515-24.

64. Pemetrexed. In LiverTox: Clinical and Research Information on Drug-Induced Liver Injury. Bethesda (MD); 2012.

65. Meriggi F, Di Biasi B, Caliolo C, Zaniboni A. The potential role of pemetrexed in gastrointestinal cancer. Chemotherapy. 2008;54:1-8.

66. Xu QY, Xie MJ, Huang J, Wang ZW. Effect of circ MTHFD2 on resistance to pemetrexed in gastric cancer through regulating expression of miR-124. Eur Rev Med Pharmacol Sci. 2019;23:10290-10,299.

67. Cohen SS, Flaks JG, Barner HD, Loeb MR, Lichtenstein J. The Mode of Action of 5-Fluorouracil and Its Derivatives. Proc Natl Acad Sci U S A. 1958;44:1004-12.

68. Longley DB, Harkin DP, Johnston PG. 5-fluorouracil: mechanisms of action and clinical strategies. Nat Rev Cancer. 2003:3:330-8.

69. Dekker E, Tanis PJ, Vleugels JLA, Kasi PM, Wallace MB. Colorectal cancer. Lancet. 2019;394:1467-80.

70. Layoun ME, Wickramasinghe CD, Peralta MV, Yang EH. FluoropyrimidineInduced Cardiotoxicity: Manifestations, Mechanisms, and Management. Curr Oncol Rep. 2016;18:35.

71. Zhang N, Yin Y, Xu SJ, Chen WS. 5-Fluorouracil: mechanisms of resistance and reversal strategies. Molecules. 2008;13:1551-69.

72. Xiong W, Ai YQ, Li YF, Ye Q, Chen ZT, Qin JY, Liu QY, Wang H, Ju YH, Li WH, Li YF. Microarray Analysis of Circular RNA Expression Profile Associated with 5-Fluorouracil-Based Chemoradiation Resistance in Colorectal Cancer Cells. Biomed Res Int. 2017;2017:8421614.

73. He L, Zhu H, Zhou S, Wu T, Wu H, Yang H, Mao H, SekharKathera C, Janardhan A, Edick AM, et al. Wnt pathway is involved in 5-FU drug resistance of colorectal cancer cells. Exp Mol Med. 2018;50:101.

74. Summerer I, Niyazi M, Unger K, Pitea A, Zangen V, Hess J, Atkinson MJ, Belka C, Moertl S, Zitzelsberger $\mathrm{H}$. Changes in circulating microRNAs after radiochemotherapy in head and neck cancer patients. Radiat Oncol. 2013;8:296.

75. Carmichael J. The role of gemcitabine in the treatment of other tumours. $\mathrm{Br}$ J Cancer. 1998;78(Suppl 3):21-5.

76. Yan L, Liu G, Cao H, Zhang H, Shao F. Hsa_circ_0035483 sponges hsa-miR335 to promote the gemcitabine-resistance of human renal cancer cells by autophagy regulation. Biochem Biophys Res Commun. 2019;519:172-8.

77. Wattanawongdon W, Hahnvajanawong C, Namwat N, Kanchanawat S, Boonmars T, Jearanaikoon P, Leelayuwat C, Techasen A, Seubwai W. Establishment and characterization of gemcitabine-resistant human cholangiocarcinoma cell lines with multidrug resistance and enhanced invasiveness. Int J Oncol. 2015;47:398-410.

78. Xie B, Wang S, Jiang N, Li JJ. Cyclin B1/CDK1-regulated mitochondrial bioenergetics in cell cycle progression and tumor resistance. Cancer Lett. 2019:443:56-66

79. Binenbaum Y. Na'ara S, Gil Z: Gemcitabine resistance in pancreatic ductal adenocarcinoma. Drug Resist Updat. 2015;23:55-68.

80. Xu C, Yu Y, Ding F. Microarray analysis of circular RNA expression profiles associated with gemcitabine resistance in pancreatic cancer cells. Oncol Rep. 2018;40:395-404.

81. Jin X, Pan Y, Wang L, Ma T, Zhang L, Tang AH, Billadeau DD, Wu H, Huang $H$. Fructose-1,6-bisphosphatase Inhibits ERK Activation and Bypasses Gemcitabine Resistance in Pancreatic Cancer by Blocking IQGAP1-MAPK Interaction. Cancer Res. 2017;77:4328-41.

82. Kagawa S, Takano S, Yoshitomi H, Kimura F, Satoh M, Shimizu H, Yoshidome $\mathrm{H}$, Ohtsuka M, Kato A, Furukawa K, et al. Akt/mTOR signaling pathway is crucial for gemcitabine resistance induced by Annexin II in pancreatic cancer cells. J Surg Res. 2012;178:758-67.

83. Shao F, Huang M, Meng F, Huang Q. Circular RNA Signature Predicts Gemcitabine Resistance of Pancreatic Ductal Adenocarcinoma. Front Pharmacol. 2018;9:584.

84. Skrypek N, Vasseur R, Vincent A, Duchene B, Van Seuningen I, Jonckheere N. The oncogenic receptor ErbB2 modulates gemcitabine and irinotecan/SN-38 chemoresistance of human pancreatic cancer cells via hCNT1 transporter and multidrug-resistance associated protein MRP-2. Oncotarget. 2015;6:10853-10,867.

85. Ding Y, Cao F, Sun H, Wang Y, Liu S, Wu Y, Cui Q, Mei W, Li F. Exosomes derived from human umbilical cord mesenchymal stromal cells deliver exogenous miR-145-5p to inhibit pancreatic ductal adenocarcinoma progression. Cancer Lett. 2019;442:351-61.

86. Sofias AM, Dunne M, Storm G, Allen C. The battle of "nano" paclitaxel. Adv Drug Deliv Rev. 2017;122:20-30.
87. Prota AE, Bargsten K, Zurwerra D, Field JJ, Diaz JF, Altmann KH, Steinmetz MO. Molecular mechanism of action of microtubule-stabilizing anticancer agents. Science. 2013;339:587-90

88. $\mathrm{Xu} \mathrm{JH}, \mathrm{Hu} \mathrm{SL}$, Shen GD, Shen G. Tumor suppressor genes and their underlying interactions in paclitaxel resistance in cancer therapy. Cancer Cell Int. 2016;16:13.

89. Kanakkanthara A, Miller JH. MicroRNAs: novel mediators of resistance to microtubule-targeting agents. Cancer Treat Rev. 2013;39:161-70.

90. Campos-Parra AD, Lopez-Urrutia E, Orozco Moreno LT, Lopez-Camarillo C, Meza-Menchaca T, Figueroa Gonzalez G, Bustamante Montes LP, PerezPlasencia C. Long Non-Coding RNAs as New Master Regulators of Resistance to Systemic Treatments in Breast Cancer. Int J Mol Sci. 2018;19:2711.

91. Sakamoto J, Matsui T, Kodera Y. Paclitaxel chemotherapy for the treatment of gastric cancer. Gastric Cancer. 2009;12:69-78.

92. Liu YY, Zhang LY, Du WZ. Circular RNA circ-PVT1 contributes to paclitaxel resistance of gastric cancer cells through the regulation of ZEB1 expression by sponging miR-124-3p. Biosci Rep. 2019;39:BSR20193045.

93. He X, Su W, Zhou Y, Ge X, Zhou J, Ou C. CircPVT1: a bridge linking Hippo pathway and human cancers. Ann Transl Med. 2018;6:S91.

94. Chen Q, Deng X, Hu X, Guan S, He M, Wang Y, Wei B, Zhang J, Zhao H, Yao W, et al. Breast Cancer Risk-Associated SNPs in the mTOR Promoter Form De Novo KLF5- and ZEB1-Binding Sites that Influence the Cellular Response to Paclitaxel. Mol Cancer Res. 2019;17:2244-56.

95. Sakata J, Utsumi F, Suzuki S, Niimi K, Yamamoto E, Shibata K, Senga T, Kikkawa F, Kajiyama H. Inhibition of ZEB1 leads to inversion of metastatic characteristics and restoration of paclitaxel sensitivity of chronic chemoresistant ovarian carcinoma cells. Oncotarget. 2017;8:99482-99,494.

96. Pokhriyal R, Hariprasad R, Kumar L, Hariprasad G. Chemotherapy Resistance in Advanced Ovarian Cancer Patients. Biomark Cancer. 2019;11: $1179299 \times 19860815$

97. Kumar A, Hoskins PJ, Tinker AV. Dose-dense paclitaxel in advanced ovarian cancer. Clin Oncol (R Coll Radiol). 2015:27:40-7.

98. Zhang S, Cheng J, Quan C, Wen H, Feng Z, Hu Q, Zhu J, Huang Y, Wu X. circCELSR1 (hsa circ 0063809) Contributes to Paclitaxel Resistance of Ovarian Cancer Cells by Regulating FOXR2 Expression via miR-1252. Mol Ther Nucleic Acids. 2019;19:718-30.

99. Delaloge S, Perol D, Courtinard C, Brain E, Asselain B, Bachelot T, Debled M, Dieras V, Campone M, Levy C, et al. Paclitaxel plus bevacizumab or paclitaxel as first-line treatment for HER2-negative metastatic breast cancer in a multicenter national observational study. Ann Oncol. 2016;27:1725-32.

100. Ma J, Fang L, Yang Q, Hibberd S, Du WW, Wu N, Yang BB. Posttranscriptional regulation of AKT by circular RNA angiomotin- like 1 mediates chemoresistance against paclitaxel in breast cancer cells. Aging (Albany NY). 2019;11:11369-11,381.

101. Xu N, Chen S, Liu Y, Li W, Liu Z, Bian X, Ling C, Jiang M. Profiles and Bioinformatics Analysis of Differentially Expressed Circrnas in Taxol-Resistant Non-Small Cell Lung Cancer Cells. Cell Physiol Biochem. 2018;48:2046-60.

102. Andreoli M, Persico M, Kumar A, Orteca N, Kumar V, Pepe A, Mahalingam S, Alegria $A E$, Petrella $L$, Sevciunaite $L$, et al. Identification of the first inhibitor of the GBP1:PIM1 interaction. Implications for the development of a new class of anticancer agents against paclitaxel resistant cancer cells. J Med Chem. 2014;57:7916-32.

103. McGrail DJ, Khambhati NN, Qi MX, Patel KS, Ravikumar N, Brandenburg CP, Dawson MR. Alterations in ovarian cancer cell adhesion drive taxol resistance by increasing microtubule dynamics in a FAK-dependent manner. Sci Rep. 2015;5:9529.

104. Kim YW, Kim EY, Jeon D, Liu JL, Kim HS, Choi JW, Ahn WS. Differential microRNA expression signatures and cell type-specific association with Taxol resistance in ovarian cancer cells. Drug Des Devel Ther. 2014;8:293-314.

105. Catuogno S, Cerchia L, Romano G, Pognonec P, Condorelli G, de Franciscis V. miR-34c may protect lung cancer cells from paclitaxel-induced apoptosis. Oncogene. 2013;32:341-51.

106. Li X, Yang B, Ren H, Xiao T, Zhang L, Li L, Li M, Wang X, Zhou H, Zhang W. Hsa_circ_0002483 inhibited the progression and enhanced the Taxol sensitivity of non-small cell lung cancer by targeting miR-182-5p. Cell Death Dis. 2019;10:953.

107. Yu W, Peng W, Sha H, Li J. Hsa_circ_0003998 Promotes Chemoresistance via Modulation of miR-326 in Lung Adenocarcinoma Cells. Oncol Res. 2019;27:623-8.

108. Dudekula DB, Panda AC, Grammatikakis I, De S, Abdelmohsen K, Gorospe M. Circlnteractome: A web tool for exploring circular RNAs and their interacting proteins and microRNAs. RNA Biol. 2016;13:34-42. 
109. Pan YJ, Wan J, Wang CB. MiR-326: Promising Biomarker for Cancer. Cancer Manag Res. 2019;11:10411-10,418.

110. Chua DT, Sham JS, Au GK. A phase II study of docetaxel and cisplatin as first-line chemotherapy in patients with metastatic nasopharyngeal carcinoma. Oral Oncol. 2005;41:589-95.

111. Hong $X$, Liu N, Liang $Y$, He Q, Yang $X$, Lei $Y$, Zhang $P$, Zhao $Y$, He S, Wang $Y$, et al. Circular RNA CRIM1 functions as a ceRNA to promote nasopharyngeal carcinoma metastasis and docetaxel chemoresistance through upregulating FOXQ1. Mol Cancer. 2020;19:33.

112. Feng J, Xu L, Ni S, Gu J, Zhu H, Wang H, Zhang S, Zhang W, Huang J. Involvement of FoxQ1 in NSCLC through regulating EMT and increasing chemosensitivity. Oncotarget. 2014;5:9689-702.

113. Gabizon AA, Patil Y, La-Beck NM. New insights and evolving role of pegylated liposomal doxorubicin in cancer therapy. Drug Resist Updat. 2016:29:90-106.

114. Shang J, Chen WM, Wang ZH, Wei TN, Chen ZZ, Wu WB. CircPAN3 mediates drug resistance in acute myeloid leukemia through the miR-153-5p/miR183-5p-XIAP axis. Exp Hematol. 2019;70:42-54 e43.

115. Carter BZ, Mak DH, Schober WD, Dietrich MF, Pinilla C, Vassilev LT, Reed JC, Andreeff M. Triptolide sensitizes AML cells to TRAlL-induced apoptosis via decrease of XIAP and p53-mediated increase of DR5. Blood. 2008;111:374250.

116. Shafei A, El-Bakly W, Sobhy A, Wagdy O, Reda A, Aboelenin O, Marzouk A, El Habak K, Mostafa R, Ali MA, Ellithy M. A review on the efficacy and toxicity of different doxorubicin nanoparticles for targeted therapy in metastatic breast cancer. Biomed Pharmacother. 2017;95:1209-18.

117. Gao D, Zhang X, Liu B, Meng D, Fang K, Guo Z, Li L. Screening circular RNA related to chemotherapeutic resistance in breast cancer. Epigenomics. 2017; 9:1175-88.

118. Christowitz C, Davis T, Isaacs A, van Niekerk G, Hattingh S, Engelbrecht AM. Mechanisms of doxorubicin-induced drug resistance and drug resistant tumour growth in a murine breast tumour model. BMC Cancer. 2019;19:757.

119. Chen JM, Bai JY, Yang KX. Effect of resveratrol on doxorubicin resistance in breast neoplasm cells by modulating PI3K/Akt signaling pathway. IUBMB Life. 2018;70:491-500.

120. Huynh FC, Jones FE. MicroRNA-7 inhibits multiple oncogenic pathways to suppress HER2Delta16 mediated breast tumorigenesis and reverse trastuzumab resistance. PLoS One. 2014;9:e114419.

121. Hsiao YC, Yeh MH, Chen YJ, Liu JF, Tang CH, Huang WC. Lapatinib increases motility of triple-negative breast cancer cells by decreasing miRNA-7 and inducing Raf-1/MAPK-dependent interleukin-6. Oncotarget. 2015;6:3796537,978 .

122. Liang Y, Song X, Li Y, Su P, Han D, Ma T, Guo R, Chen B, Zhao W, Sang Y, et al. circKDM4C suppresses tumor progression and attenuates doxorubicin resistance by regulating miR-548p/PBLD axis in breast cancer. Oncogene. 2019:38:6850-66.

123. Li A, Yan Q, Zhao X, Zhong J, Yang H, Feng Z, Du Y, Wang Y, Wang Z, Wang $H$, et al. Decreased expression of PBLD correlates with poor prognosis and functions as a tumor suppressor in human hepatocellular carcinoma. Oncotarget. 2016;7:524-37.

124. Shaili E. Platinum anticancer drugs and photochemotherapeutic agents: recent advances and future developments. Sci Prog. 2014;97:20-40.

125. Zhang S, Lovejoy KS, Shima JE, Lagpacan LL, Shu Y, Lapuk A, Chen Y, Komori T, Gray JW, Chen X, et al. Organic cation transporters are determinants of oxaliplatin cytotoxicity. Cancer Res. 2006;66:8847-57.

126. Abu N, Hon KW, Jeyaraman S, Yahaya A, Abdullah NM, Mustangin M, Sulaiman SA, Jamal R, Ab-Mutalib NS. Identification of differentially expressed circular RNAs in chemoresistant colorectal cancer. Epigenomics. 2019:11:875-84

127. Hon KW, Ab-Mutalib NS, Abdullah NMA, Jamal R, Abu N. Extracellular Vesicle-derived circular RNAs confers chemoresistance in Colorectal cancer Sci Rep. 2019;9:16497.

128. Wang $X$, Zhang H, Yang H, Bai M, Ning T, Deng T, Liu R, Fan Q, Zhu K, Li J, et al. Exosome-delivered circRNA promotes glycolysis to induce chemoresistance through the miR-122-PKM2 axis in colorectal cancer. Mol Oncol. 2020;14:539-55.

129. Dilruba S, Kalayda GV. Platinum-based drugs: past, present and future. Cancer Chemother Pharmacol. 2016;77:1103-24.

130. Galluzzi L, Senovilla L, Vitale I, Michels J, Martins I, Kepp O, Castedo M, Kroemer G. Molecular mechanisms of cisplatin resistance. Oncogene. 2012; 31:1869-83.
131. Huang MS, Yuan FQ, Gao Y, Liu JY, Chen YX, Wang CJ, He BM, Zhou HH, Liu ZQ. Circular RNA screening from EIF3a in lung cancer. Cancer Med. 2019;8: 4159-68.

132. Dong Y, Xu T, Zhong S, Wang B, Zhang H, Wang X, Wang P, Li G, Yang S. Circ_0076305 regulates cisplatin resistance of non-small cell lung cancer via positively modulating STAT3 by sponging miR-296-5p. Life Sci. 2019;239: 116984.

133. Xu C, Li S, Chen T, Hu H, Ding C, Xu Z, Chen J, Liu Z, Lei Z, Zhang HT, et al, miR-296-5p suppresses cell viability by directly targeting PLK1 in non-small cell lung cancer. Oncol Rep. 2016;35:497-503.

134. Sun CY, Nie J, Huang JP, Zheng GJ, Feng B. Targeting STAT3 inhibition to reverse cisplatin resistance. Biomed Pharmacother. 2019;117:109135.

135. Zheng F, Xu R. CircPVT1 contributes to chemotherapy resistance of lung adenocarcinoma through miR-145-5p/ABCC1 axis. Biomed Pharmacother. 2020;124:109828.

136. Huang MS, Liu JY, Xia XB, Liu YZ, Li X, Yin JY, Peng JB, Wu L, Zhang W, Zhou HH, Liu ZQ. Hsa_circ_0001946 Inhibits Lung Cancer Progression and Mediates Cisplatin Sensitivity in Non-small Cell Lung Cancer via the Nucleotide Excision Repair Signaling Pathway. Front Oncol. 2019;9:508.

137. Zhang GH, Ren JC, Luo M, Cui J, Du Y, Yang D, Cui S, Wang X, Wu W, Cao J, Xia ZL. Association of BER and NER pathway polymorphism haplotypes and micronucleus frequencies with global DNA methylation in benzene-exposed workers of China: Effects of DNA repair genes polymorphisms on genetic damage. Mutat Res Genet Toxicol Environ Mutagen. 2019;839:13-20.

138. Biazzo A, De Paolis M. Multidisciplinary approach to osteosarcoma. Acta Orthop Belg. 2016;82:690-8.

139. Botter SM, Neri D, Fuchs B. Recent advances in osteosarcoma. Curr Opin Pharmacol. 2014;16:15-23.

140. Kun-Peng Z, Xiao-Long M, Lei Z, Chun-Lin Z, Jian-Ping H, Tai-Cheng Z. Screening circular RNA related to chemotherapeutic resistance in osteosarcoma by RNA sequencing. Epigenomics. 2018;10:1327-46.

141. Zhu KP, Zhang CL, Ma XL, Hu JP, Cai T, Zhang L. Analyzing the Interactions of mRNAs and ncRNAs to Predict Competing Endogenous RNA Networks in Osteosarcoma Chemo-Resistance. Mol Ther. 2019;27:518-30.

142. Zhang H, Yan J, Lang X, Zhuang Y. Expression of circ_001569 is upregulated in osteosarcoma and promotes cell proliferation and cisplatin resistance by activating the Wnt/beta-catenin signaling pathway. Oncol Lett. 2018;16: 5856-62.

143. Kun-Peng Z, Xiao-Long M, Chun-Lin Z. Overexpressed circPVT1, a potential new circular RNA biomarker, contributes to doxorubicin and cisplatin resistance of osteosarcoma cells by regulating ABCB1. Int J Biol Sci. 2018;14:321-30.

144. Genovese I, llari A, Assaraf YG, Fazi F, Colotti G. Not only P-glycoprotein: Amplification of the ABCB1-containing chromosome region 7q21 confers multidrug resistance upon cancer cells by coordinated overexpression of an assortment of resistance-related proteins. Drug Resist Updat. 2017;32:23-46.

145. Kun-Peng Z, Chun-Lin Z, Jian-Ping H, Lei Z. A novel circulating hsa_circ_ 0081001 act as a potential biomarker for diagnosis and prognosis of osteosarcoma. Int J Biol Sci. 2018;14:1513-20.

146. Ikeda K. Recent advances in medical management of hepatocellular carcinoma. Hepatol Res. 2019;49:14-32.

147. Wagner AD, Syn NL, Moehler M, Grothe W, Yong WP, Tai BC, Ho J, Unverzagt S. Chemotherapy for advanced gastric cancer. Cochrane Database Syst Rev. 2017:8:CD004064.

148. Kamat AM, Hahn NM, Efstathiou JA, Lerner SP, Malmstrom PU, Choi W, Guo CC, Lotan Y, Kassouf W. Bladder cancer. Lancet. 2016:388:2796-810.

149. Bookman MA. Optimal primary therapy of ovarian cancer. Ann Oncol. 2016; 27(Suppl 1):i58-62.

150. Sun XS, Sun SR, Guevara N, Fakhry N, Marcy PY, Lassalle S, Peyrottes I, Bensadoun RJ, Lacout A, Santini J, et al. Chemoradiation in anaplastic thyroid carcinomas. Crit Rev Oncol Hematol. 2013;86:290-301.

151. Luo Y, Fu Y, Huang R, Gao M, Liu F, Gui R, Nie X. CircRNA_101505 sensitizes hepatocellular carcinoma cells to cisplatin by sponging miR-103 and promotes oxidored-nitro domain-containing protein 1 expression. Cell Death Dis. 2019;5:121.

152. Li W, Li X, Wang W, Yi M, Zhou Y, Zheng P, Xiong W, Yang J, Peng S, $M c C a r t h y ~ J B$, et al. Tumor suppressor gene Oxidored-nitro domaincontaining protein 1 regulates nasopharyngeal cancer cell autophagy, metabolism, and apoptosis in vitro. Int J Biochem Cell Biol. 2013;45:2016-26.

153. Huang X, Li Z, Zhang Q, Wang W, Li B, Wang L, Xu Z, Zeng A, Zhang X, Zhang $X$, et al. Circular RNA AKT3 upregulates PIK3R1 to enhance cisplatin resistance in gastric cancer via miR-198 suppression. Mol Cancer. 2019;18:71. 
154. Xue M, Li G, Fang X, Wang L, Jin Y, Zhou Q. hsa_circ_0081143 promotes cisplatin resistance in gastric cancer by targeting miR-646/CDK6 pathway. Cancer Cell Int. 2019;19:25.

155. Huang XX, Zhang Q, Hu H, Jin Y, Zeng AL, Xia YB, Xu L. A novel circular RNA circFN1 enhances cisplatin resistance in gastric cancer via sponging miR-182-5p. J Cell Biochem. 2020;1-12.

156. Zhao Z, Ji M, Wang Q, He N, Li Y. Circular RNA Cdr1as Upregulates SCAl to Suppress Cisplatin Resistance in Ovarian Cancer via miR-1270 Suppression. Mol Ther Nucleic Acids. 2019;18:24-33.

157. Chi BJ, Zhao DM, Liu L, Yin XZ, Wang FF, Bi S, Gui SL, Zhou SB, Qin WB, Wu DM, Wang SQ. Downregulation of hsa_circ_0000285 serves as a prognostic biomarker for bladder cancer and is involved in cisplatin resistance. Neoplasma. 2019;66:197-202.

158. Chen J, Sun Y, Ou Z, Yeh S, Huang CP, You B, Tsai YC, Sheu TJ, Zu X, Chang C. Androgen receptor-regulated circFNTA activates KRAS signaling to promote bladder cancer invasion. EMBO Rep. 2020;21:e48467.

159. Rachner TD, Coleman R, Hadji P, Hofbauer LC. Bone health during endocrine therapy for cancer. Lancet Diabetes Endocrinol. 2018;6:901-10.

160. Huang $\mathrm{H}$, Tindall DJ. The role of the androgen receptor in prostate cancer. Crit Rev Eukaryot Gene Expr. 2002;12:193-207.

161. Santos AF, Huang $H$, Tindall DJ. The androgen receptor: a potential target for therapy of prostate cancer. Steroids. 2004;69:79-85.

162. Labrie F. Mechanism of action and pure antiandrogenic properties of flutamide. Cancer. 1993;72:3816-27.

163. Roviello G, Cappelletti MR, Zanotti L, Gobbi A, Senti C, Bottini A, Ravelli A, Bonetta A, Paganini G, Generali D. Targeting the androgenic pathway in elderly patients with castration-resistant prostate cancer: A meta-analysis of randomized trials. Medicine (Baltimore). 2016;95:e4636.

164. Cao S, Ma T, Ungerleider N, Roberts C, Kobelski M, Jin L, Concha M, Wang X, Baddoo M, Nguyen HM, et al. Circular RNAs add diversity to androgen receptor isoform repertoire in castration-resistant prostate cancer. Oncogene. 2019;38:7060-72.

165. Greene J, Baird AM, Casey O, Brady L, Blackshields G, Lim M, O'Brien O, Gray SG, McDermott R, Finn SP. Circular RNAs are differentially expressed in prostate cancer and are potentially associated with resistance to enzalutamide. Sci Rep. 2019:9:10739.

166. Wu G, Sun Y, Xiang Z, Wang K, Liu B, Xiao G, Niu Y, Wu D, Chang C. Preclinical study using circular RNA 17 and micro RNA 181c-5p to suppress the enzalutamide-resistant prostate cancer progression. Cell Death Dis. 2019;10:37.

167. Xiang Z, Xu C, Wu G, Liu B, Wu D. CircRNA-UCK2 Increased TET1 Inhibits Proliferation and Invasion of Prostate Cancer Cells Via Sponge MiRNA-7675p. Open Med (Wars). 2019;14:833-42.

168. Lash TL, Lien EA, Sorensen HT, Hamilton-Dutoit S. Genotype-guided tamoxifen therapy: time to pause for reflection? Lancet Oncol. 2009;10:82533.

169. Early Breast Cancer Trialists' Collaborative G. Aromatase inhibitors versus tamoxifen in early breast cancer: patient-level meta-analysis of the randomised trials. Lancet. 2015;386:1341-52.

170. Mills JN, Rutkovsky AC, Giordano A. Mechanisms of resistance in estrogen receptor positive breast cancer: overcoming resistance to tamoxifen/ aromatase inhibitors. Curr Opin Pharmacol. 2018;41:59-65.

171. Farhan M, Aatif M, Dandawate $P$, Ahmad A. Non-coding RNAs as Mediators of Tamoxifen Resistance in Breast Cancers. Adv Exp Med Biol. 2019;1152: 229-41.

172. Sang $Y$, Chen B, Song X, Li Y, Liang Y, Han D, Zhang N, Zhang H, Liu Y, Chen T, et al. circRNA_0025202 Regulates Tamoxifen Sensitivity and Tumor Progression via Regulating the miR-182-5p/FOXO3a Axis in Breast Cancer. Mol Ther. 2019:27:1638-52

173. Pellegrino M, Rizza P, Dona A, Nigro A, Ricci E, Fiorillo M, Perrotta I, Lanzino M, Giordano C, Bonofiglio D, et al. FoxO3a as a Positive Prognostic Marker and a Therapeutic Target in Tamoxifen-Resistant Breast Cancer. Cancers (Basel). 2019;11:1858

174. Liang $Y$, Song $X$, Li Y, Ma T, Su P, Guo R, Chen B, Zhang H, Sang Y, Liu Y, et al. Targeting the circBMPR2/miR-553/USP4 Axis as a Potent Therapeutic Approach for Breast Cancer. Mol Ther Nucleic Acids. 2019;17:347-61.

175. Li Y, Jiang D, Zhang Q, Liu X, Cai Z. Ubiquitin-specific protease 4 inhibits breast cancer cell growth through the upregulation of PDCD4. Int J Mol Med. 2016:38:803-11.

176. Baudino TA. Targeted Cancer Therapy: The Next Generation of Cancer Treatment. Curr Drug Discov Technol. 2015;12:3-20.
177. Pakkala S, Ramalingam SS. Personalized therapy for lung cancer: striking a moving target. JCI Insight. 2018;3:e120858.

178. Forde PM, Ettinger DS. Managing acquired resistance in EGFR-mutated nonsmall cell lung cancer. Clin Adv Hematol Oncol. 2015;13:528-32.

179. Liu YT, Han XH, Xing PY, Hu XS, Hao XZ, Wang Y, Li JL, Zhang ZS, Yang ZH, Shi YK. Circular RNA profiling identified as a biomarker for predicting the efficacy of Gefitinib therapy for non-small cell lung cancer. J Thorac Dis. 2019;11:1779-87.

180. Zhou Y, Zheng X, Xu B, Chen L, Wang Q, Deng H, Jiang J. Circular RNA hsa_ circ_0004015 regulates the proliferation, invasion, and TKI drug resistance of non-small cell lung cancer by miR-1183/PDPK1 signaling pathway. Biochem Biophys Res Commun. 2019;508:527-35.

181. Li D, Mullinax JE, Aiken T, Xin H, Wiegand G, Anderson A, Thorgeirsson S, Avital I, Rudloff U. Loss of PDPK1 abrogates resistance to gemcitabine in label-retaining pancreatic cancer cells. BMC Cancer. 2018;18:772.

182. Al-Zeer MA, Xavier A, Abu Lubad M, Sigulla J, Kessler M, Hurwitz R, Meyer TF. Chlamydia trachomatis Prevents Apoptosis Via Activation of PDPK1-MYC and Enhanced Mitochondrial Binding of Hexokinase II. EBioMedicine. 2017; 23:100-10.

183. Janne PA, Yang JC, Kim DW, Planchard D, Ohe Y, Ramalingam SS, Ahn MJ, Kim SW, Su WC, Horn L, et al. AZD9291 in EGFR inhibitor-resistant nonsmall-cell lung cancer. N Engl J Med. 2015;372:1689-99.

184. Yu HA, Arcila ME, Rekhtman N, Sima CS, Zakowski MF, Pao W, Kris MG, Miller VA, Ladanyi M, Riely GJ. Analysis of tumor specimens at the time of acquired resistance to EGFR-TKI therapy in 155 patients with EGFR-mutant lung cancers. Clin Cancer Res. 2013;19:2240-7.

185. Leonetti A, Sharma S, Minari R, Perego P, Giovannetti E, Tiseo M. Resistance mechanisms to osimertinib in EGFR-mutated non-small cell lung cancer. $\mathrm{Br}$ J Cancer. 2019;121:725-37.

186. Chen T, Luo J, Gu Y, Huang J, Luo Q, Yang Y. Comprehensive analysis of circular RNA profiling in AZD9291-resistant non-small cell lung cancer cell lines. Thorac Cancer. 2019;10:930-41.

187. Lugo TG, Pendergast AM, Muller AJ, Witte ON. Tyrosine kinase activity and transformation potency of bcr-abl oncogene products. Science. 1990;247:1079-82.

188. Linev AJ, Ivanov HJ, Zhelyazkov IG, Ivanova H, Goranova-Marinova VS, Stoyanova VK. Mutations Associated with Imatinib Mesylate Resistance Review. Folia Med (Plovdiv). 2018;60:617-23.

189. Melo JV, Chuah C. Resistance to imatinib mesylate in chronic myeloid leukaemia. Cancer Lett. 2007;249:121-32.

190. Pan Y, Lou J, Wang H, An N, Chen H, Zhang Q, Du X. CircBA9.3 supports the survival of leukaemic cells by up-regulating c-ABL1 or BCR-ABL1 protein levels. Blood Cells Mol Dis. 2018;73:38-44.

191. Ping L, Jian-Jun C, Chu-Shu L, Guang-Hua L, Ming Z. High circ_100053 predicts a poor outcome for chronic myeloid leukemia and is involved in imatinib resistance. Oncol Res. 2019. https://doi.org/10.3727/ $096504018 \times 15412701483326$

192. Byun DJ, Wolchok JD, Rosenberg LM, Girotra M. Cancer immunotherapy immune checkpoint blockade and associated endocrinopathies. Nat Rev Endocrinol. 2017;13:195-207.

193. Keir ME, Liang SC, Guleria I, Latchman YE, Qipo A, Albacker LA, Koulmanda M, Freeman GJ, Sayegh MH, Sharpe AH. Tissue expression of PD-L1 mediates peripheral T cell tolerance. J Exp Med. 2006;203:883-95.

194. Sharpe AH, Pauken KE. The diverse functions of the PD1 inhibitory pathway. Nat Rev Immunol. 2018;18:153-67.

195. Kazandjian D, Suzman DL, Blumenthal G, Mushti S, He K, Libeg M, Keegan P, Pazdur R. FDA Approval Summary: Nivolumab for the Treatment of Metastatic Non-Small Cell Lung Cancer With Progression On or After Platinum-Based Chemotherapy. Oncologist. 2016;21:634-42.

196. Skrzypski M, Jassem J. Consolidation systemic treatment after radiochemotherapy for unresectable stage III non-small cell lung cancer Cancer Treat Rev. 2018;66:114-21.

197. Pai-Scherf L, Blumenthal GM, Li H, Subramaniam S, Mishra-Kalyani PS, He K, Zhao H, Yu J, Paciga M, Goldberg KB, et al. FDA Approval Summary: Pembrolizumab for Treatment of Metastatic Non-Small Cell Lung Cancer: First-Line Therapy and Beyond. Oncologist. 2017;22:1392-9.

198. Ren D, Hua Y, Yu B, Ye X, He Z, Li C, Wang J, Mo Y, Wei X, Chen Y, et al. Predictive biomarkers and mechanisms underlying resistance to PD1/PD-L1 blockade cancer immunotherapy. Mol Cancer. 2020;19:19.

199. Zhang PF, Pei X, Li KS, Jin LN, Wang F, Wu J, Zhang XM. Circular RNA circFGFR1 promotes progression and anti-PD-1 resistance by sponging miR381-3p in non-small cell lung cancer cells. Mol Cancer. 2019;18:179. 
200. Jiang K, Li J, Zhang J, Wang L, Zhang Q, Ge J, Guo Y, Wang B, Huang Y, Yang $T$, et al. SDF-1/CXCR4 axis facilitates myeloid-derived suppressor cells accumulation in osteosarcoma microenvironment and blunts the response to anti-PD-1 therapy. Int Immunopharmacol. 2019;75:105818.

201. Kamphorst AO, Pillai RN, Yang S, Nasti TH, Akondy RS, Wieland A, Sica GL, Yu K, Koenig L, Patel NT, et al. Proliferation of PD-1+ CD8 T cells in peripheral blood after PD-1-targeted therapy in lung cancer patients. Proc Natl Acad Sci U S A. 2017;114:4993-8.

202. Seo YD, Jiang X, Sullivan KM, Jalikis FG, Smythe KS, Abbasi A, Vignali M, Park JO, Daniel SK, Pollack SM, et al. Mobilization of CD8(+) T Cells via CXCR4 Blockade Facilitates PD-1 Checkpoint Therapy in Human Pancreatic Cancer. Clin Cancer Res. 2019;25:3934-45.

203. Hanahan D, Weinberg RA. The hallmarks of cancer. Cell. 2000;100:57-70.

204. Hanahan D, Weinberg RA. Hallmarks of cancer: the next generation. Cell. 2011;144:646-74

205. Gutschner T, Diederichs S. The hallmarks of cancer: a long non-coding RNA point of view. RNA Biol. 2012;9:703-19.

206. Van Roosbroeck K, Calin GA. Cancer Hallmarks and MicroRNAs: The Therapeutic Connection. Adv Cancer Res. 2017:135:119-49.

207. Suto T, Yokobori T, Yajima R, Morita H, Fujii T, Yamaguchi S, Altan B, Tsutsumi S, Asao T, Kuwano H. MicroRNA-7 expression in colorectal cancer is associated with poor prognosis and regulates cetuximab sensitivity via EGFR regulation. Carcinogenesis. 2015;36:338-45.

208. Doherty J, Baehrecke EH. Life, death and autophagy. Nat Cell Biol. 2018;20: $1110-7$.

209. Xiong H, Ni Z, He J, Jiang S, Li X, He J, Gong W, Zheng L, Chen S, Li B, et al. LnCRNA HULC triggers autophagy via stabilizing Sirt1 and attenuates the chemosensitivity of HCC cells. Oncogene. 2017;36:3528-40.

210. Chen QN, Wei CC, Wang ZX, Sun M. Long non-coding RNAs in anti-cancer drug resistance. Oncotarget. 2017:8:1925-36.

211. Wang H, Zhu LJ, Yang YC, Wang ZX, Wang R. MiR-224 promotes the chemoresistance of human lung adenocarcinoma cells to cisplatin via regulating $\mathrm{G}(1) / \mathrm{S}$ transition and apoptosis by targeting p21(WAF1/CIP1). Br J Cancer. 2014;111:339-54.

212. Xu T, Yan S, Wang M, Jiang L, Ma P, Lu B, Chen Q, Wei C, Wang Z. LncRNA UCA1 Induces Acquired Resistance to Gefitinib by Epigenetically Silencing CDKN1A Expression in Non-small-Cell Lung Cancer. Front Oncol. 2020;10:656.

213. Chen LL, Yang L. Regulation of circRNA biogenesis. RNA Biol. 2015;12:381-8.

214. Li X, Yang L, Chen LL. The Biogenesis, Functions, and Challenges of Circular RNAs. Mol Cell. 2018;71:428-42.

215. Lopez-Jimenez E, Rojas AM, Andres-Leon E. RNA sequencing and Prediction Tools for Circular RNAs Analysis. Adv Exp Med Biol. 2018;1087:17-33.

216. Liu J, Li D, Luo H, Zhu X. Circular RNAs: The star molecules in cancer. Mol Asp Med. 2019;70:141-52.

217. Li T, Shao Y, Fu L, Xie Y, Zhu L, Sun W, Yu R, Xiao B, Guo J. Plasma circular RNA profiling of patients with gastric cancer and their droplet digital RTPCR detection. J Mol Med (Berl). 2018;96:85-96.

218. Cui C, Yang J, Li X, Liu D, Fu L, Wang X. Functions and mechanisms of circular RNAs in cancer radiotherapy and chemotherapy resistance. Mol Cancer. 2020;19:58

219. Marteijn JA, Lans H, Vermeulen W, Hoeijmakers JH. Understanding nucleotide excision repair and its roles in cancer and ageing. Nat Rev Mol Cell Biol. 2014;15:465-81.

220. Fresno Vara JA, Casado E, de Castro J, Cejas P, Belda-Iniesta C, GonzalezBaron M. PI3K/Akt signalling pathway and cancer. Cancer Treat Rev. 2004;30: 193-204.

221. Martin-Orozco E, Sanchez-Fernandez A, Ortiz-Parra I, Ayala-San Nicolas M. WNT Signaling in Tumors: The Way to Evade Drugs and Immunity. Front Immunol. 2019:10:2854.

222. Shibue T, Weinberg RA. EMT, CSCS, and drug resistance: the mechanistic link and clinical implications. Nat Rev Clin Oncol. 2017;14:611-29.

223. Nieto MA, Huang RY, Jackson RA, Thiery JP. Emt: 2016. Cell. 2016;166:21-45.

224. Norouzi S, Gorgi Valokala M, Mosaffa F, Zirak MR, Zamani P, Behravan J. Crosstalk in cancer resistance and metastasis. Crit Rev Oncol Hematol. 2018; 132:145-53.

225. Nandy SB, Lakshmanaswamy R. Cancer Stem Cells and Metastasis. Prog Mol Biol Transl Sci. 2017;151:137-76.

226. Su PH, Hsu YW, Huang RL, Chen LY, Chao TK, Liao CC, Chen CW, Wu Tl, Mao SP, Balch C, Lai HC. TET1 promotes 5hmC-dependent stemness, and inhibits a $5 \mathrm{hmC}$-independent epithelial-mesenchymal transition, in cervical precancerous lesions. Cancer Lett. 2019;450:53-62.
227. de Fraipont F, Gazzeri S, Cho WC, Eymin B. Circular RNAs and RNA Splice Variants as Biomarkers for Prognosis and Therapeutic Response in the Liquid Biopsies of Lung Cancer Patients. Front Genet. 2019;10:390.

228. Kessler MD, Pawar NR, Martin SS, Antalis TM, O'Connor TD. Improving Cancer Detection and Treatment with Liquid Biopsies and ptDNA. Trends Cancer. 2018:4:643-54.

229. Li L, Li W, Chen N, Zhao H, Xu G, Zhao Y, Pan X, Zhang X, Zhou L, Yu D, et al. FLI1 Exonic Circular RNAs as a Novel Oncogenic Driver to Promote Tumor Metastasis in Small Cell Lung Cancer. Clin Cancer Res. 2019;25:1302-17.

230. Deng T, Tang J, Zhou L, Duan H. Effective targeted therapy based on dynamic monitoring of gene mutations in non-small cell lung cancer. Transl Lung Cancer Res. 2019;8:532-8

231. Rupaimoole R, Slack FJ. MicroRNA therapeutics: towards a new era for the management of cancer and other diseases. Nat Rev Drug Discov. 2017;16: 203-22.

232. Bach DH, Lee SK, Sood AK. Circular RNAs in Cancer. Mol Ther Nucleic Acids. 2019;16:118-29.

\section{Publisher's Note}

Springer Nature remains neutral with regard to jurisdictional claims in published maps and institutional affiliations.
Ready to submit your research? Choose BMC and benefit from:

- fast, convenient online submission

- thorough peer review by experienced researchers in your field

- rapid publication on acceptance

- support for research data, including large and complex data types

- gold Open Access which fosters wider collaboration and increased citations

- maximum visibility for your research: over $100 \mathrm{M}$ website views per year

At $\mathrm{BMC}$, research is always in progress.

Learn more biomedcentral.com/submissions 